\title{
Slow Oscillations in the Mouse Hippocampus Entrained by Nasal Respiration
}

\author{
Yevgenij Yanovsky, ${ }^{1}$ Mareva Ciatipis, ${ }^{2}$ Andreas Draguhn, ${ }^{1}$ Adriano B.L. Tort, ${ }^{3 \star}$ and Jurij Brankačk ${ }^{1 \star}$ \\ ${ }^{1}$ Institute for Physiology and Pathophysiology, University Heidelberg, 69120 Heidelberg, Germany, ${ }^{2}$ Spinal Cord Injury Center, Heidelberg University \\ Hospital, 69118 Heidelberg, Germany, and ${ }^{3}$ Brain Institute, Federal University of Rio Grande do Norte, RN 59056-450 Natal, Rio Grande do Norte, Brazil
}

Different types of network oscillations occur in different behavioral, cognitive, or vigilance states. The rodent hippocampus expresses prominent $\theta$ oscillations at frequencies between 4 and $12 \mathrm{~Hz}$, which are superimposed by phase-coupled $\gamma$ oscillations $(30-100 \mathrm{~Hz})$. These patterns entrain multineuronal activity over large distances and have been implicated in sensory information processing and memory formation. Here we report a new type of oscillation at near- $\theta$ frequencies $(2-4 \mathrm{~Hz})$ in the hippocampus of urethane-anesthetized mice. The rhythm is highly coherent with nasal respiration and with rhythmic field potentials in the olfactory bulb: hence, we called it hippocampal respiration-induced oscillations. Despite the similarity in frequency range, several features distinguish this pattern from locally generated $\theta$ oscillations: hippocampal respiration-induced oscillations have a unique laminar amplitude profile, are resistant to atropine, couple differently to $\gamma$ oscillations, and are abolished when nasal airflow is bypassed by tracheotomy. Hippocampal neurons are entrained by both the respiration-induced rhythm and concurrent $\theta$ oscillations, suggesting a direct interaction between endogenous activity in the hippocampus and nasal respiratory inputs. Our results demonstrate that nasal respiration strongly modulates hippocampal network activity in mice, providing a long-range synchronizing signal between olfactory and hippocampal networks.

Key words: $\gamma$ oscillations; hippocampus; network oscillations; rodent; $\theta$ rhythm; urethane

\section{Introduction}

The mammalian entorhinal-hippocampal system expresses a variety of network oscillations that provide a temporal framework for coordinated neuronal activity (Buzsáki and Draguhn, 2004). The resulting spatiotemporal discharge patterns are causally involved in memory formation, consolidation, and retrieval (Montgomery and Buzsáki, 2007; Girardeau et al., 2009; Buzsáki and Moser, 2013). Accordingly, different behavioral states go along with different hippocampal oscillations at $\theta(4-12 \mathrm{~Hz}), \gamma$ (30-100 Hz), or ripple $(150-250 \mathrm{~Hz})$ frequency (Ylinen et al., 1995a; Csicsvari et al., 1999; Buzsáki et al., 2003; Buzsáki and Silva, 2012).

Hippocampal $\theta$ oscillations occur during active waking and REM sleep (Vanderwolf, 1969; Buzsáki, 2002). Together with superimposed $\gamma$ oscillations, they organize the sequential activation of hippocampal neurons (O'Keefe and Recce, 1993; Skaggs et

Received Dec. 18, 2013; revised March 17, 2014; accepted March 20, 2014.

Author contributions:Y.Y., A.D., and J.B. designed research; Y.Y. and M.C. performed research; Y.Y., A.B.L.T., and J.B. analyzed data; Y.Y., A.D., A.B.L.T., and J.B. wrote the paper.

This work was supported by the Deutsche Forschungsgemeinschaft (SFB 636/B06), Bundesministerium für Bildung und Forschung (Bernstein Center for Computational Neurosciences 01GQ1003A and German-Brazil Cooperation Grant 01DN12098), and the Brazilian National Council of Technological and Scientific Development. We thank Steven E. Fox for his valuable suggestions on an earlier manuscript version, Nadine Zuber and Reinhold Wojciechowski for excellent technical support, and Valery I. Kukushka for programming.

The authors declare no competing financial interests.

${ }^{*}$ A.B.L.T. and J.B. contributed equally to this work.

Correspondence should be addressed to Dr. Jurij Brankačk, Institute for Physiology and Pathophysiology, University Heidelberg, Im Neuenheimer Feld 326, 69120 Heidelberg, Germany. E-mail: jurij.brankack@physiologie.uniheidelberg.de.

DOI:10.1523/JNEUROSCI.5287-13.2014

Copyright $\odot 2014$ the authors $\quad 0270-6474 / 14 / 345949-16 \$ 15.00 / 0$ al., 1996; Harris et al., 2002). The mechanisms underlying $\theta$ oscillations include intrinsic resonance properties of pyramidal cells (Leung and Yu, 1998; Hu et al., 2002), selective activation of interneurons (Chapman and Lacaille, 1999; Dragoi et al., 1999), and cholinergic and GABAergic inputs from the septum (Stewart and Fox, 1991; Buzsáki, 2002). Consistently, urethane-induced $\theta$ oscillations are sensitive to the muscarinic acetylcholine receptor antagonist atropine (Kramis et al., 1975; Buzsáki et al., 1986; but see Stewart and Fox, 1989).

The hippocampus receives multimodal sensory inputs from the entorhinal cortex. Because of its strong links with the olfactory system, the hippocampal formation has long been regarded as an olfactory sensory area (Cajal, 1911). Indeed, it is involved in odor discrimination in humans (Eichenbaum et al., 1983) and rodents (Eichenbaum et al., 1988, 1989), as well as in odorrelated associative learning (Eichenbaum, 1998; Alvarez et al., 2002). Anatomically, olfactory bulb (OB) neurons project to the lateral entorhinal cortex in rodents (Kosel et al., 1981; Wouterlood and Nederlof, 1983; Shipley and Adamek, 1984; Wouterlood et al., 1985; Kerr et al., 2007) from where disynaptic and polysynaptic afferents reach the dentate gyrus (DG) (Wilson and Steward, 1978; Schwerdtfeger et al., 1990; Liu and Bilkey, 1997).

Little is known, however, about the influence of olfactory inputs on hippocampal network activity. Based on recordings from urethane-anesthetized mice, here we demonstrate that nasal respiration causes prominent $2-4 \mathrm{~Hz}$ local field potential (LFP) oscillations in the DG. The unique laminar profile and several further properties reveal a clear distinction between hippocampal $\theta$ and respiration-driven oscillations. Unit discharges and membrane potential of hippocampal neurons are entrained by the 
respiration-driven oscillation, underlining its impact on hippocampal activity patterns. Our results suggest that respirationinduced oscillations have a role in information processing in hippocampal networks.

\section{Materials and Methods}

In brief, we recorded from the hippocampus of 51 female urethaneanesthetized mice with simultaneous measurement of respiratory activity through a piezoelectric sensor placed below the animal's chest. Intracellular recordings with simultaneous LFP acquisition were performed in 13 animals, three of which were subjected to tail pinching during anesthesia; in the remaining 10 , we replaced tail pinching with electric stimulation of the brainstem, targeted at the nucleus pontis oralis (NPO), to induce arousal without diminishing the stability of intracellular recordings. In 27 mice, we implanted NeuroNexus silicon probes with 16 recording sites separated by $100 \mu \mathrm{m}$ across the CA1-DG axis. Anatomical landmarks were identified by stimulation of the angular bundle (Brankačk et al., 1993). Recording sites started at the stratum oriens and reached the ventral blade of the DG. In 6 anesthetized animals, we simultaneously recorded from the OB. Atropine $(50 \mathrm{mg} / \mathrm{kg}$ i.p.) was used in eight mice. Six mice were tracheotomized before the recording session. Below we provide further methodological details.

\section{Ethics statement}

This study was performed in accordance with guidelines of the European Science Foundation (2001) and the U.S. National Institutes of Health Guide for the Care and Use of Laboratory Animals (Institute of Laboratory Animal Research, 1996) and has been approved by the Governmental Supervisory Panel on Animal Experiments of Baden Württemberg at Karlsruhe (35-9185.81/G-30/08). All efforts were made to minimize animal suffering and to reduce the number of animals used. Because of the system-level approach of our study, alternatives to in vivo techniques were not available.

\section{Animal care and housing conditions}

Mice (C57BL/6N) were purchased at 28 or $45 \mathrm{~d}$ of age from Charles River. Animals were housed in groups of four or five inside a ventilated Scantainer (Scanbur BK A/S Denmark) on an inverted 12/12 h light/dark cycle (light on 8:00 P.M.) for a minimum of 2 weeks. Animals had free access to water and food. The animals were killed with an overdose of ketaminexylazine after the experiment.

\section{Animal preparation}

Fifty-one female C57BL/6N mice weighting 20-30 g (12-16 weeks old) were anesthetized with a mixture of urethane $(1.5 \mathrm{~g} / \mathrm{kg})$ and ketaminexylazine ( $10 \mathrm{mg} / \mathrm{kg}, 1 \mathrm{mg} / \mathrm{kg}$, i.p.). The level of anesthesia was maintained so that hindlimb pinching produced no reflex movement. Supplemental doses of urethane $(0.2 \mathrm{~g} / \mathrm{kg})$ were delivered as needed (approximately every $1.5 \mathrm{~h}$ ). The animals were mounted on a stereotaxic frame (Kopf Instruments), and body temperature was maintained at $38^{\circ} \mathrm{C}$. After exposure of the skull, holes of $0.5-1.0 \mathrm{~mm}$ in diameter were drilled above the dorsal hippocampus and $\mathrm{OB}$ according to stereotaxic coordinates (Paxinos and Franklin, 2001). The dura mater was carefully removed and Teflon-insulated platinum electrodes $(125 \mu \mathrm{m}, \mathrm{FHC})$ were implanted into the OB (4.0 mm AP, $0.8 \mathrm{~mm} \mathrm{ML}, 2.0 \mathrm{~mm} \mathrm{DV}$ ). A pair of $125 \mu \mathrm{m}$ tungsten electrodes (MicroProbes) was positioned at the angular bundle $(-4.2 \mathrm{~mm} \mathrm{AP}, 2.75 \mathrm{~mm} \mathrm{ML}, 1.8 \mathrm{~mm} \mathrm{DV})$ for perforant path stimulation $(80-300 \mu \mathrm{A})$ and additionally at the lateral olfactory tract $(4.0 \mathrm{~mm} \mathrm{AP}$, $0.8 \mathrm{~mm} \mathrm{ML}, 2.5 \mathrm{~mm} \mathrm{DV})$. In experiments with intracellular recordings, stimulation of the brainstem NPO (-6.2 mm AP, 1.0 mm ML, 4.8-5.0 $\mathrm{mm} \mathrm{DV}, 8-30 \mu \mathrm{A}, 250 \mathrm{~Hz}$ for $1 \mathrm{~s}$ ) was used to replace urethane-induced sleep-like LFP activity by wake-like patterns (Clement et al., 2008). Extracellular field potentials were recorded from the dorsal hippocampus (stereotaxic coordinates relative to bregma: $-2.0 \mathrm{~mm} \mathrm{AP,} 1.5 \mathrm{~mm} \mathrm{ML}$, 2.2-2.5 $\mathrm{mm}$ DV for the deepest position) using 16-channel silicone probes $(\mathrm{A} 1 \times 16-5 \mathrm{~mm}-100-177-\mathrm{A} 16$ or A1 $\times 16-5 \mathrm{~mm}-100-703-\mathrm{A} 16$, NeuroNexus Technologies). In all animals, respiration was monitored by recording the chest wall movements using a piezoelectric device (EPZ20MS64, EKULIT) located beneath the animal's body; in 2 animals, we compared recordings obtained with the piezoelectric sensor with those of a thermosensor located at the nostrils and found fully coherent estimation of respiratory activity by both methods (data not shown). In six mice, tracheotomy was performed under additional local lidocaine anesthesia. Atropine $(50 \mathrm{mg} / \mathrm{kg}$ ) was applied intraperitoneally in eight mice.

\section{Drug preparation}

Urethane, ketamine-xylazine, and atropine were freshly dissolved in isotonic $(0.9 \%) \mathrm{NaCl}$ solution. All solutions were heated to $38^{\circ} \mathrm{C}$ before application.

\section{Electrophysiology}

Extracellular signals were filtered $(1-500 \mathrm{~Hz})$, amplified (EXT-16DX and/or EXT 10-2F, npi, Tamm), digitized (2 kHz) using the CED 1401 board (CED), and stored for offline analyses with custom-written MATLAB routines (Mathworks). Intracellular recordings of hippocampal neurons were obtained with high-impedance quartz-glass micropipettes (o.d.1.0/i.d.0.5 mm; impedance: $60-120 \mathrm{~m} \Omega$ ) pulled with the P-2000 puller (Sutter Instruments). Recording electrodes were filled with $1 \mathrm{M}$ potassium acetate and slowly lowered in $5 \mu \mathrm{m}$ steps using the Micropositioner 2660 (Kopf Instruments). Axoclamp 900A (Molecular Devices) in current-clamp mode with a bridge circuit was used to amplify intracellular signals. For unit recordings, signals were filtered $(0-10 \mathrm{kHz})$ and digitized at $20 \mathrm{kHz}$. All neurons included in this study showed stable membrane potentials below $-50 \mathrm{mV}$ without holding current and generated action potentials with overshoots. Juxtacellular recordings were performed by using quartz-glass micropipettes with impedance lowered to $10-20 \mathrm{M} \Omega$. DG neurons had mean resting membrane potential of $-66.0 \pm 2.9 \mathrm{mV}$ with an overshoot of $14.9 \pm 3.2 \mathrm{mV}$; CA1 neurons had mean resting membrane potential of $-58.3 \pm 1.6 \mathrm{mV}$ (significantly depolarized compared with DG neurons; $p<0.05$, $t$ test) with an overshoot of $14.9 \pm 2.5 \mathrm{mV}$. The intracellularly recorded units in CA1 and DG were most likely principal cells because of the duration of action potentials $(>1.0 \mathrm{~ms})$, low level of spontaneous activity, and strong frequency accommodation to depolarizing square pulses (Ylinen et al., 1995b; Freund and Buzsáki, 1996). Extracellularly recorded multiunit activity (MUA) from the 16-channel probes was obtained by high pass filtering $(500 \mathrm{~Hz})$. Spike times were defined by setting a threshold above background noise upon visual inspection of individual MUA signals. Because MUA was obtained from single probe contacts, we did not attempt to identify single-unit cell types in these signals.

\section{Data analysis}

Data were analyzed offline in MATLAB (Mathworks) using built-in and custom-written routines.

Spectral analysis, cross-correlation, and coherence analysis. Power spectral density (PSD) was calculated by means of the Welch periodogram method using the pwelch.m function from the Signal Processing Toolbox (50\% overlapping $4 \mathrm{~s}$ Hamming windows). Time-frequency power decomposition was obtained by means of the spectrogram. $m$ function; in Figures 1 and 3, we used sliding windows of $4 \mathrm{~s}$ and $50 \mathrm{~ms}$ time step; in Figure 5, we used windows of $2 \mathrm{~s}$ and $100 \mathrm{~ms}$ step. The cross-correlation shown in Figure $6 E$ was computed using the xcorr.m function, with the "coeff" option to normalize values between -1 and 1 . Phase coherence was obtained by means of the mscohere. $m$ function from the Signal Processing Toolbox, using $4 \mathrm{~s}$ windows with $50 \%$ overlap.

Spike-field coupling. To assess spike-phase coupling, we first filtered the LFP signal within the frequency range of interest. Filtering was obtained through a linear finite impulse response filter by means of the eegfilt.m function from the EEGLAB toolbox (http://sccn.ucsd. edu/eeglab/). The filter order depends on the low-frequency cutoff and is given by 3 times the ratio of the sampling frequency to the low-frequency cutoff (rounded to the nearest integer toward zero). The eegfil. $m$ function calls the filtfilt.m routine, which in turn applies the filter forward and then again backwards to ensure that phase delays introduced by the filter are nullified (Delorme and Makeig, 2004). The phase time series was obtained from the analytical representation of the filtered signal based on the Hilbert transform (hilbert.m function). Spike times were then associated with the corresponding instantaneous phases of the filtered signal, used to compute the spike-phase distribution. Coupling strength was 
A

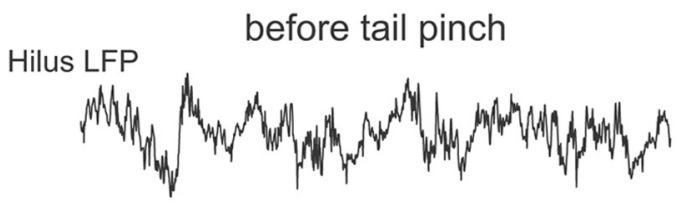

B

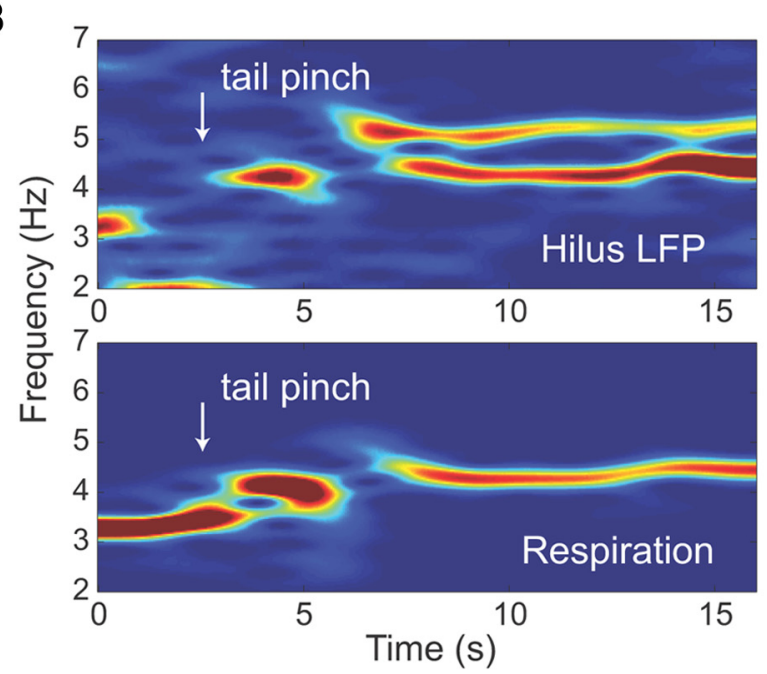

after tail pinch

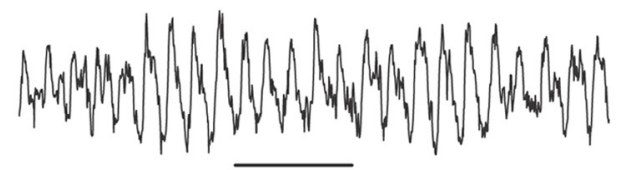

$1 \mathrm{~s}$

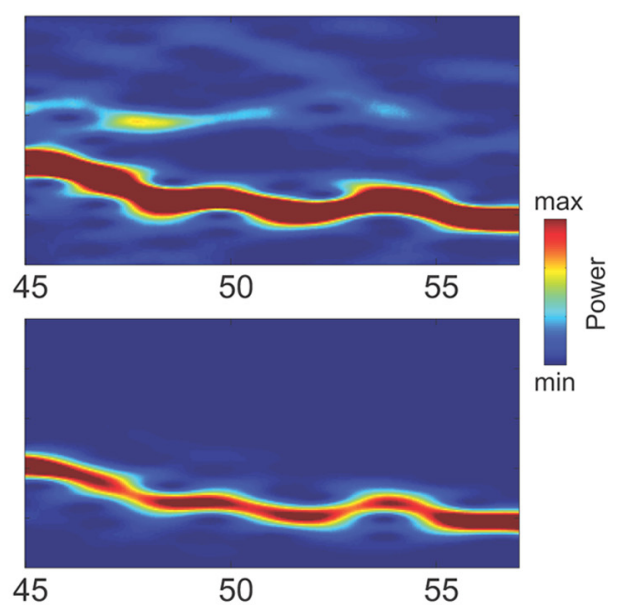

45

D

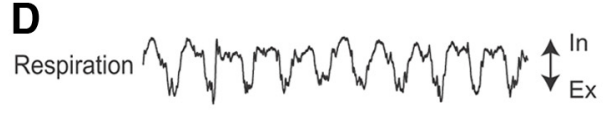

C

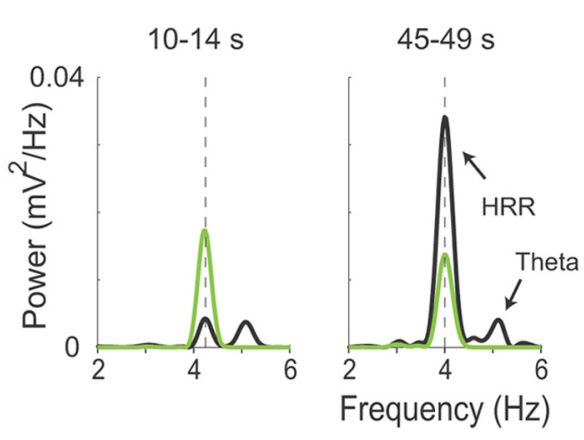

$49-53 \mathrm{~s}$
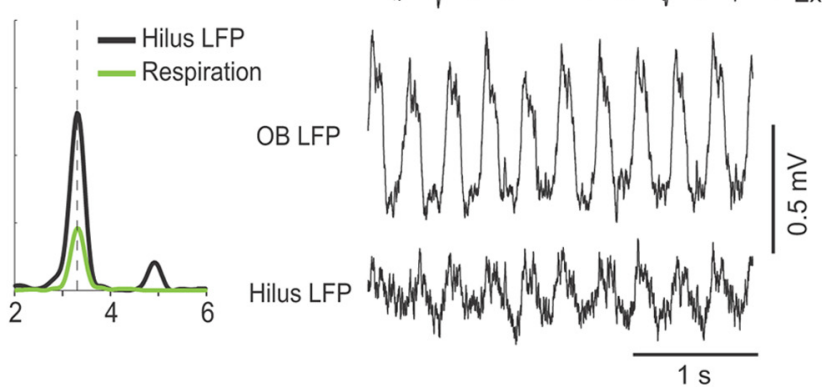

Figure 1. The mouse hippocampus simultaneously produces $\theta$ oscillations and a slower respiration-induced rhythm (HRR). $A$, LFP from the hilus of a urethane-anesthetized mouse before and after tail pinching (see Results). $\boldsymbol{B}$, Time-frequency analysis of LFP (top) and respiratory activity (bottom). Tail pinching increases respiration rate and induces two hippocampal oscillations of close but different frequencies. C, Power spectra of LFP (black) and respiration (green) in different time windows after tail pinching. Peak frequency of the slower rhythm (HRR) closely follows respiration frequency (dashed line), whereas the peak frequency of the faster rhythm $(\theta)$ is more stable. $\boldsymbol{D}$, Examples of simultaneous LFP recordings from the $\mathrm{OB}$ (middle) and hilus (bottom) exhibiting synchronized activity with respiration (top). In, Inspiration; Ex, expiration.

obtained by the length $R$ of the mean vector over all phases projected on the unit circle, that is $R=\left\|1 / \mathrm{N} \Sigma \exp \left(i \phi_{j}\right)\right\|$, where $\phi_{j}, j=1: \mathrm{N}$ are the phases associated with spikes, and $i$ is the imaginary number. The reference signal for $\theta$ used in Figure 6 was taken from the fissure, whereas the reference signal for the respiration-induced rhythm was taken from the DG hilus.

Depth profile of $\theta$, respiration-induced rhythm, and $\gamma$ oscillations. Periods of $\theta$ and respiration-driven oscillations evoked by tail pinches or stimulation of the brainstem NPO were visually selected. For isolation of respiration-driven cycles, the signals were filtered between $\sim 2$ and $\sim 4$ $\mathrm{Hz}$ (the precise cutoff depended on respiration rate), and between $\sim 4$ and $\sim 6 \mathrm{~Hz}$ for $\theta$ cycles (the precise cutoff depended on the power peak in the PSD). Recordings from the hippocampal fissure served as reference for $\theta$ (Brankačk et al., 1993), whereas recordings from the hilus were used as reference for the respiration-induced rhythm (see below for laminar profiles). Peaks of identified cycles of $\theta$ at the hippocampal fissure or the respiratory oscillations at the hilus served as triggers for averaging the filtered signals across the 16 electrode positions of the silicon probes $(n=$ 30 waves). Similarly, peaks of identified $\gamma(30-100 \mathrm{~Hz})$ cycles were used for average ( $n=50$ waves). Voltage profiles as a function of recording depth were computed from the averaged evoked potentials in response to perforant path stimulation. These signals were subsequently used to estimate probe location (Brankačk et al., 1993) (for an example, see Fig. 8C, top). Granule cell layers were localized by the polarity reversal of perforant path-evoked potentials. In addition, the hippocampal fissure was identified from the amplitude maximum of $\theta$, and the CA1 pyramidal cell layer from the $180^{\circ} \theta$ phase reversal. The hilus was estimated at the middle between both granule cell layers. Voltage profiles from averaged $\theta$ and respiration-driven oscillations were used to compute current source density (CSD) as previously described (Brankačk et al., 1993). For averaging across animals, the depth profiles from different mice were adjusted according to the current sink in the dorsal blade of dentate molecular layer evoked by perforant path stimulation.

Identification of $\theta$ and hippocampal respiration-induced rhythm. The main criterion for differentiating hippocampal $\theta$ and respiration-driven oscillation was based on tracking respiration rate. The respiration-driven rhythm was defined as the hippocampal LFP rhythm, which peak frequency perfectly matched respiration rate. For most cases except one animal, respiration rate was lower than $\theta$ frequency (Fig. 2). Additional features that corroborated the correct division between both rhythms included analysis of depth profiles, atropine sensitivity, and dependence of nasal airflow (see Results). 
A

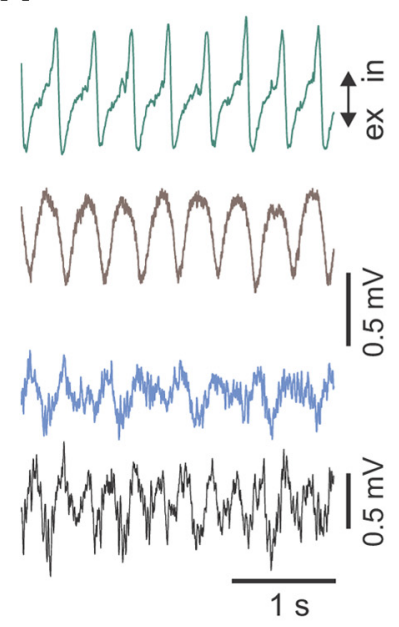

C

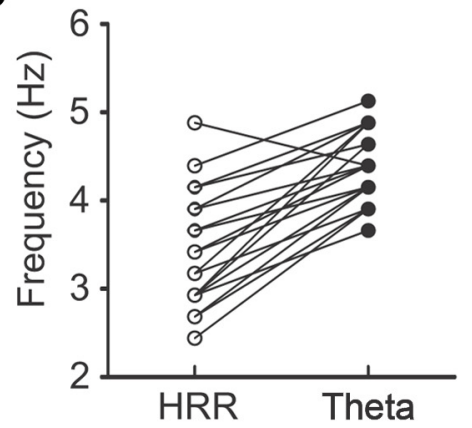

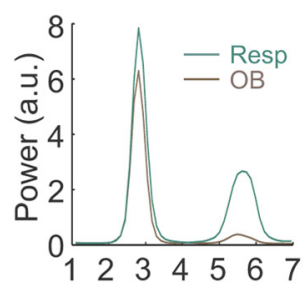

B
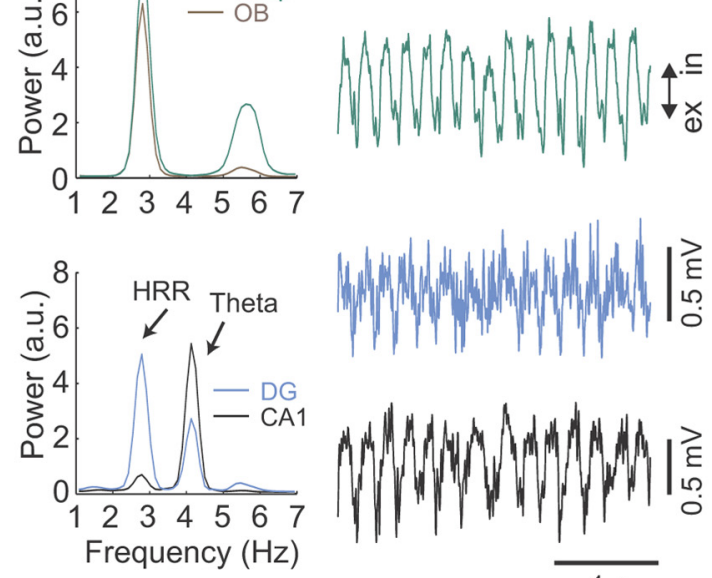

D

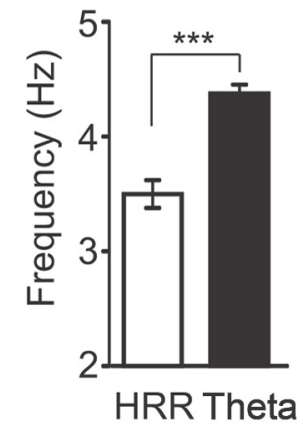

$1 \mathrm{~s}$

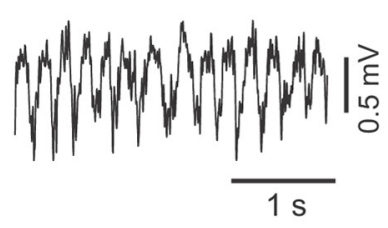

E
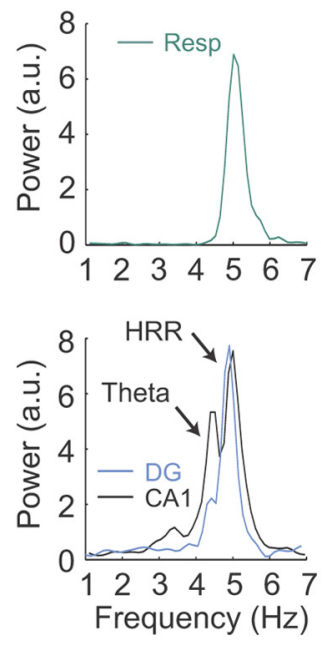

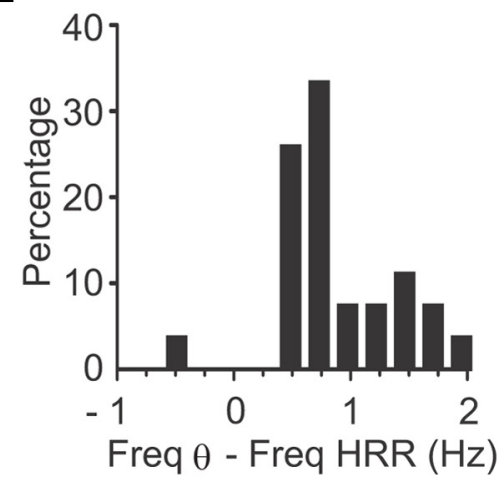

Figure 2. Respiration rate strongly influences the frequency difference between $\theta$ and the HRR. $\boldsymbol{A}, \boldsymbol{B}$, Left panels, Raw traces of LFPs simultaneously recorded from the fissure (black), DG hilus (blue), or $\mathrm{OB}$ (brown), along with respiration activity (Resp, green). Respiration rate and $\mathrm{HRR}$ are slower than $\theta$ in $\boldsymbol{A}$, whereas respiration rate and $\mathrm{HHR}$ are faster in $\boldsymbol{B}$. $\boldsymbol{C}$, Peak frequencies for $\mathrm{HRR}$ and $\theta(\theta)$. HRR is slower than $\theta$, except in one case (shown in $\boldsymbol{B})$. $\boldsymbol{D}$, Mean peak frequency for HRR and $\theta\left(n=27{ }^{* * *} p<0.0001\right.$, paired $t$ test). $\boldsymbol{E}$, Distribution of frequency differences between HRR and $\theta$ recorded simultaneously in, Inspiration; ex, expiration.

Power correlations. Band power for $\theta$ (recorded at the fissure) and respiration-induced oscillations (recorded at the hilus) was obtained using $1 \mathrm{~s}$ sliding windows with no overlap. The Pearson correlation coefficient was computed for each animal individually. Results are expressed as the mean \pm SEM correlation coefficient across animals, along with the range of $p$ values.

Cross-frequency coupling analysis. The heat maps of averaged amplitude of fast oscillations time-locked to the troughs of $\theta$ or respirationdriven oscillations shown in Figure $11 B$ were computed as previously described (Scheffzük et al., 2011). Briefly, we first obtained the time points corresponding to troughs of $\theta$ or respiration-induced oscillations. We then computed the mean amplitude envelope of filtered LFP signals centered at these time points; this procedure was performed for multiple filtered bands of $10 \mathrm{~Hz}$ bandwidth, covering $10-210 \mathrm{~Hz}$ with $1 \mathrm{~Hz}$ steps. To control for $1 / \mathrm{f}$, amplitude values for each frequency were normalized by the mean amplitude. The trace at the bottom of the heat map is the average unfiltered LFP signal also triggered by the same time points.

Phase-amplitude distribution-like plots for low $\gamma(30-50 \mathrm{~Hz})$, high $\gamma(70-90 \mathrm{~Hz})$, and the whole $\gamma$ band $(30-100 \mathrm{~Hz})$ shown in Figure $11 C, F$ were computed using $20^{\circ}$ phase bins as previously described (Tort et al., 2010). In this plot, the mean amplitude in each phase bin is normalized by the sum across bins (so that amplitude values for each animal sum to 1 , resembling a probability distribution). This procedure therefore corrects for differences in absolute $\gamma$ amplitude among animals and allows estimating group results. The phaseamplitude modulation index shown in Figure $11 C$ was computed as previously described (Tort et al., 2010); in short, this index measures how much the empirical phase-amplitude distribution deviates from the uniform distribution, which characterizes absence of coupling. The comodulation map shown in Figure $11 E$ was obtained by computing the modulation index between multiple band-filtered frequency pairs (for review, see Tort et al., 2010); we used $2 \mathrm{~Hz}$ bandwidth windows and $0.25 \mathrm{~Hz}$ steps for phase frequencies, and 10 $\mathrm{Hz}$ windows at $5 \mathrm{~Hz}$ steps for amplitude frequencies. For each animal, the "mean $\gamma$ phase" is defined from the phase-amplitude distribution as the mean phase of $\theta$ or respiration-induced rhythm weighted by $\gamma$ $(30-100 \mathrm{~Hz})$ amplitude. The phase vectors shown in Figure $11 \mathrm{~F}$ (middle) are unit-length vectors which phase represents the mean $\gamma$ phase.

\section{Histology}

Animals were deeply anesthetized and transcardially perfused with $0.9 \%$ physiological saline and $10 \%$ formalin. Brains were carefully dissected, and coronal frozen sections were cut $(50 \mu \mathrm{m})$, mounted, and stained with cresyl violet. Probe positions were verified by light microscopy.

\section{Statistics}

Data are expressed as mean ( \pm SEM). For group comparisons of normally distributed data (Kolmogorov-Smirnov test), we used $t$ test or ANOVA followed by Tukey's multiple-comparison test. For nonGaussian distributions, we used Mann-Whitney U test or Friedman test. The statistical significance of spike-phase modulation was assessed through the Rayleigh test for uniformity of phase distribution. The mean $\gamma$ phase for $\theta$ and respiration-induced oscillations was compared using the Watson-Williams test. We used $p<0.05$ to denote statistical significance. 
A
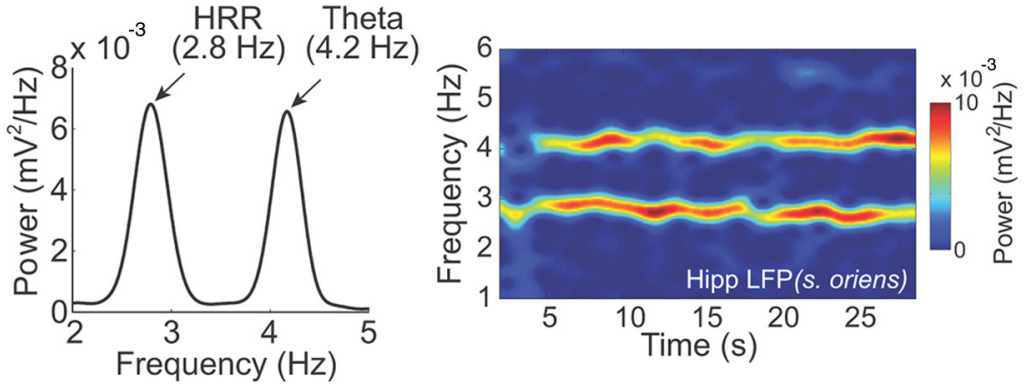

B

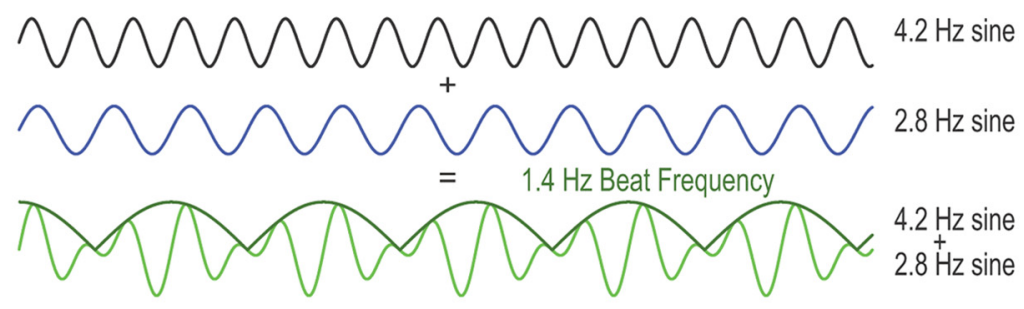

C

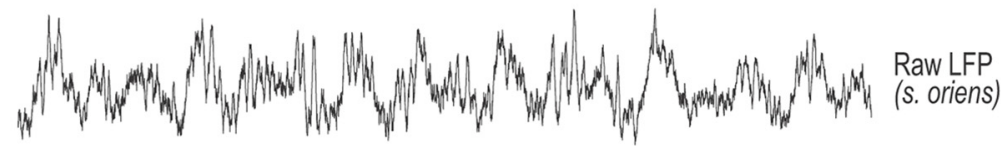

$m m m$ Theta

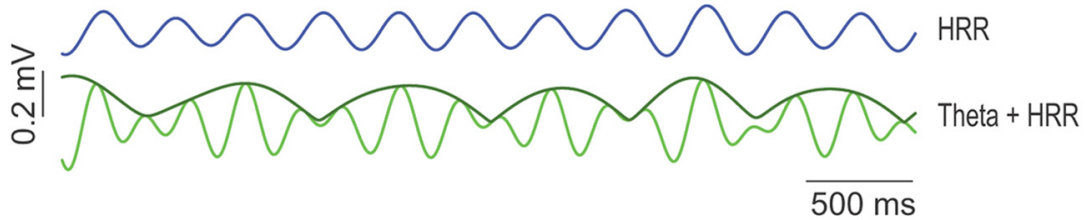

D

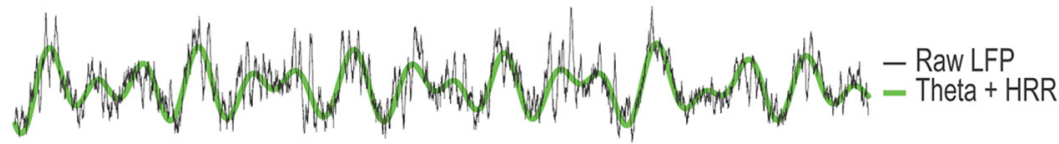

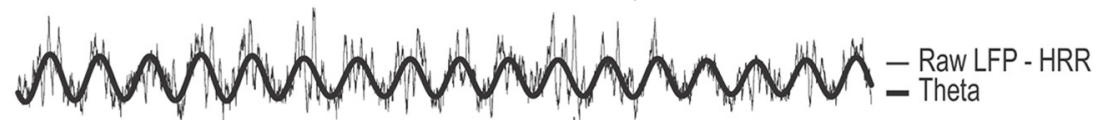

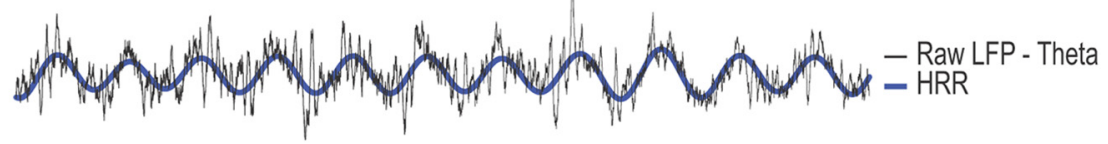

Figure 3. LFP signals simultaneous exhibiting HRR and $\theta$ oscillations show frequency beating. $\boldsymbol{A}$, Power spectrum (left) and time-frequency analysis (right) of an LFP in stratum oriens exhibiting both HRR and $\theta$ activity. $\boldsymbol{B}$, Top two traces, Artificial sine wave signals at the same frequencies as $\theta(4.2 \mathrm{~Hz})$ and HRR $(2.8 \mathrm{~Hz})$ in the actual LFP shown in $\boldsymbol{A}$. Bottom trace, Signal obtained by the sum of the two sine waves, along with its amplitude envelope. There is prominent frequency beating at $1.4 \mathrm{~Hz}$, which corresponds to the frequency difference between the two sine waves. $C$, Top three traces, Raw and $\theta$-and HRR-filtered signals for the same LFP as in $\boldsymbol{A}$. Bottom trace, Signal obtained by summing the $\theta$ - and HRR-filtered signals, along with its amplitude envelope. There is similar frequency beating in the real and artificial signals. D, Top, Raw LFP plotted along with the sum of filtered $\theta$ and HRR signals (same example as above). The main variations of LFP voltage correspond to the frequency beating. Middle, Raw LFP trace minus the HRR-filtered signal is plotted along with the $\theta$-filtered signal. Bottom, Raw LFP trace minus the $\theta$-filtered signal is plotted along with the HRR-filtered signal. In the latter two panels, it is possible to observe $\theta$ and HRR in the subtracted LFP trace, whereas in the top panel $\theta$ and HRR are not as easily discernible in the unfiltered LFP because of the frequency beating.

\section{Results}

Weak arousal elicits two independent rhythms in the hippocampus of urethane-anesthetized mice

Hippocampal LFPs of urethane-anesthetized rodents resemble slow-wave sleep activity, which is intermittently replaced by wake-like activity; this spontaneous alternation of LFP patterns is similar to the sleep-wake cycle of nonanesthetized animals
(Clement et al., 2008). Weak arousal, by tail pinching or brainstem stimulation, promptly interrupts urethane-induced sleep-like activity and evokes wake-like activity with prominent rhythms between 2 and $6 \mathrm{~Hz}$ (Kramis et al., 1975). We consistently reproduced this effect in recordings from the dorsal hippocampus of urethane-anesthetized mice (Fig. 1A, Hilus LFP). Surprisingly, however, timefrequency power analysis of hilar LFPs after tail pinching revealed two distinct rhythms between 2 and $6 \mathrm{~Hz}$ (Fig. $1 B, C$ ). The faster LFP component had relatively stable peak frequencies of $4-5 \mathrm{~Hz}$ (Fig. $2 C, D$ for group means: $4.4 \mathrm{~Hz}$; range $3.7-$ $5.1 \mathrm{~Hz}, n=27$ ), which corresponds to the atropine-sensitive $\theta$ oscillations described by Kramis et al. (1975). The slower rhythm showed continuously decreasing frequencies, starting from $\sim 4.5 \mathrm{~Hz}$ and decaying to $\sim 3.2 \mathrm{~Hz}$ within $45 \mathrm{~s}$ after tail pinching (Fig. $1 B$; see Fig. $2 D$ for group means: $3.5 \mathrm{~Hz}$; range $2.4-4.9 \mathrm{~Hz}, n=27$ ). Piezoelectrical measurement of thorax movements revealed that tail pinching induced a similar increase and slow decay of basal respiration rate (Fig. $1 B$, bottom panels). Further analysis showed that the peak frequency of the slower arousal-induced LFP rhythm matched exactly the frequency of respiration (Fig. 1C). Based on these and other results shown below, we call the slower component "hippocampal respirationinduced rhythm" (HRR) and the faster component " $\theta$ oscillations."

Thus, hippocampal networks express a slow respiration-coupled field potential oscillation in addition to $\theta$ activity upon tail pinching. Both rhythms were often observed simultaneously in hippocampal LFPs but could also occur in isolation (for an example, see Fig. $1 B$, between 53 and $57 \mathrm{~s})$. Without monitoring respiration, identification of the two components was not possible because of the small difference in their mean frequencies $(1.2 \pm 0.10$ $\mathrm{Hz}, n=27)$ and the possibility that respiration rate could sometimes exceed $\theta$ frequency (Fig. 2B). Indeed, although the frequency difference between $\theta$ and HRR was highly significant (Fig. 2D), its absolute value was $<1 \mathrm{~Hz}$ in $>60 \%$ of episodes (Fig. 2C,E). Power of $\theta$ and HRR was not correlated as revealed from 12 mice where both oscillations were simultaneously present (mean $\mathrm{r}:-0.05 \pm$ $0.07 ; n=12$; $p$ value range: 0.08 to 0.7 ). Interestingly, in LFP traces exhibiting concurrent HRR and $\theta$ oscillations, we could observe the frequency beating phenomenon, in which the amplitude envelope varied at the same frequency as the frequency difference between $\theta$ and HRR (Fig. 3); indeed, in the LFP example shown in Figure $3 D$ (top), the main voltage variations are entirely 
A
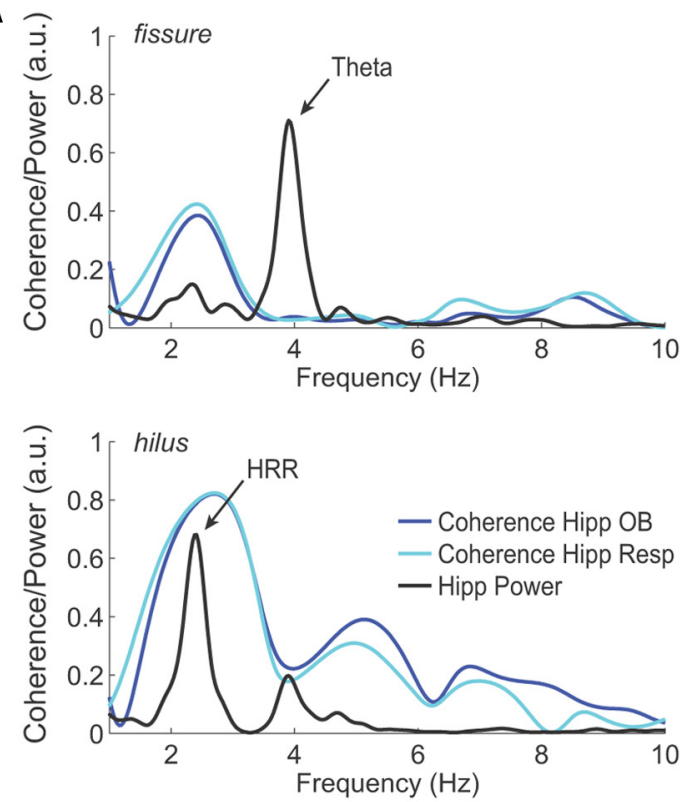

B

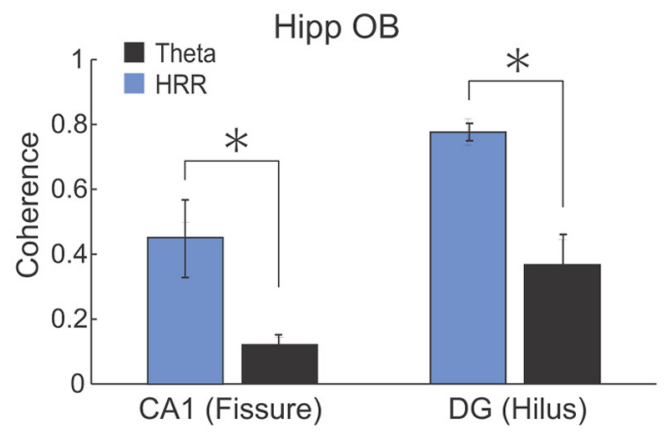

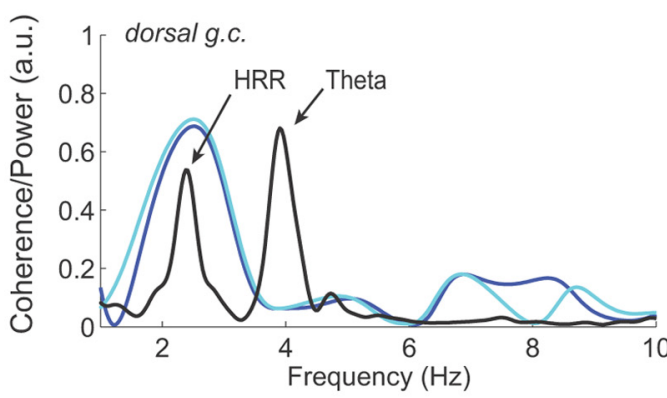

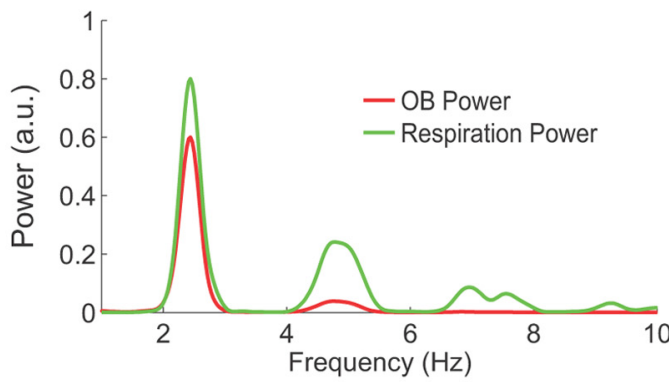

C

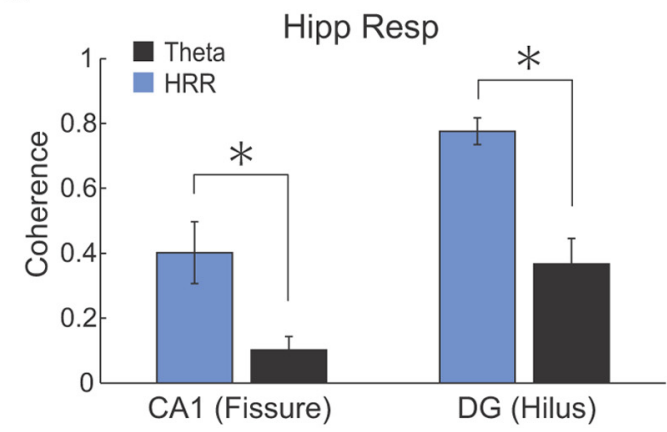

Figure 4. HRR, but not $\theta$, is coherent with respiration and OB oscillations. $A$, Representative examples of coherence spectra for hippocampal (Hipp) LFP exhibiting HRR and $\theta$. Top left panel, PSD for a fissure LFP (black) plotted along its coherence spectrum with OB LFP (dark blue) and respiration activity (Resp, light blue). Top right panel and bottom left panels, Same as before, but for LFPs recorded at the dorsal granule cell layer (g.c.) and at the dentate hilus, respectively. Lower right panel, PSD computed for respiration activity (green) and for the OB LFP (red). $\boldsymbol{B}$, Mean coherence between hippocampal and OB LFPs. There is higher HRR coherence with OB compared with $\theta$ for LFPs recorded from both CA1 fissure and DG hilus $(n=5 ; p<0.05$, paired $t$ test). C, Mean coherence between hippocampal LFPs and respiration activity. There are similar results as before $\left(n=10 ;{ }^{*} p<0.01\right.$ for CA1 and ${ }^{*} p<0.001$ for DG, paired $t$ test).

accounted for by the frequency beating. From here on, we focus our analysis on periods of wake-like LFP activity where the slower hippocampal oscillations were separated from $\theta$ oscillations by $>0.4 \mathrm{~Hz}$.

Whereas the slower LFP component in the DG was an unexpected finding, parallel field potential recordings from the $\mathrm{OB}$ confirmed the well-known respiration-entrained oscillation in this brain region (Adrian, 1950; Klingberg and Pickenhain, 1965; Fontanini and Bower, 2006). The hippocampal respirationinduced rhythm showed strong phase coherence with the slow OB rhythm, which in turn was highly coherent with respiration (Figs. $1 D$ and $4 A$ ). Group means confirmed the strong coherence between hippocampal respiratory oscillations in CA1 and DG and both $\mathrm{OB}$ activity and respiration itself (Fig. 4B,C). Coherence estimates between hippocampal and OB LFPs were clearly stronger for HRR compared with $\theta$ both in DG hilus and in CA1 fissure (Fig. $4 B ; n=5 ; p<0.05$, paired $t$ test). Similarly, coherence between respiration and LFP was larger for HRR than for $\theta$ in CA1 as well as in DG (Fig. $4 C ; n=10 ; p<0.01$, paired $t$ test). Coherence values for HRR and respiration were larger in DG compared with CA1 ( $n=10 ; p<0.005$, paired $t$ test).

\section{Hippocampal respiration-induced rhythm and $\theta$ oscillations are distinct}

The layered structure of the hippocampus allows mechanistic inferences from spatial distributions of electrical network activity called "laminar profiles." We recorded such depth profiles of $\theta$ and respiration-induced oscillations across the CA1-DG axis using 16-channel silicon probes (contact separation: $100 \mu \mathrm{m}$ ). A representative experiment from a urethane-anesthetized mouse is shown in Figure 5. Spectral decomposition of simultaneously recorded hippocampal LFPs revealed clearly different depth distributions for the power of $\theta$ and HRR across the CA1-DG axis (Fig. 5C,E, selected layers; Fig. 5D, left, all recording sites). Although power of both rhythms was low in alveus and the ventral blade of the dentate (Fig. 5C,E, top and bottom), HRR was maximal at the hilus and $\theta$ oscillations peaked at the hippocampal fissure (Fig. $5 C, E$ ), in line with previous reports (Brankačk et al., 1993). Urethane-induced $\theta$ oscillations displayed an abrupt phase reversal of $180^{\circ}$ across the CA1 pyramidal cell layer (Fig. $5 D$, right) as described previously (Buzsáki et al., 1986; Brankačk et al., 1993). In contrast, the phase of HRR exhibited no reversal at the CA1 pyramidal cell layer but showed a mild phase shift 
A
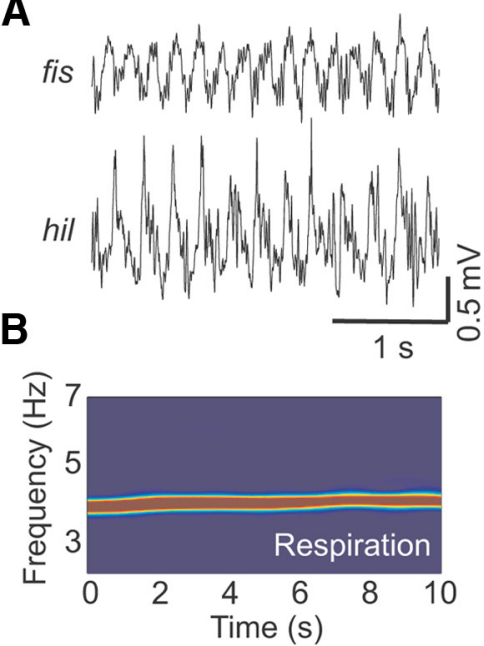

C

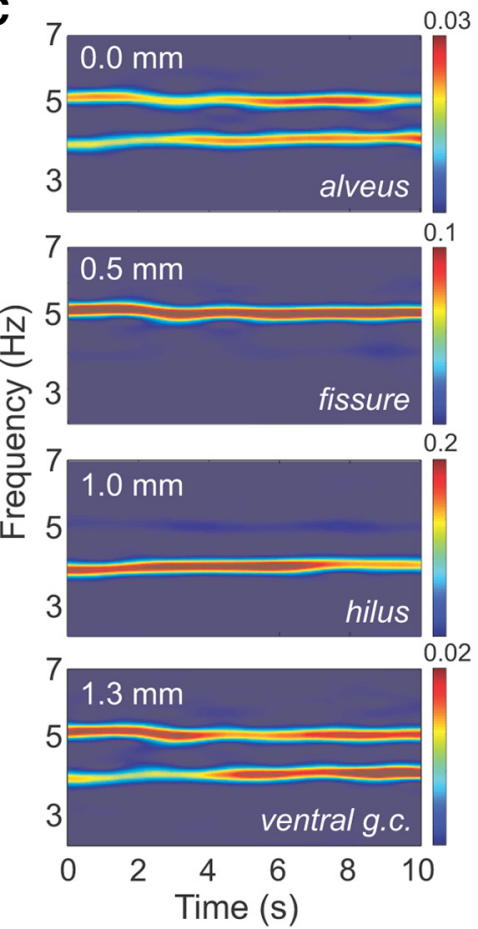

D

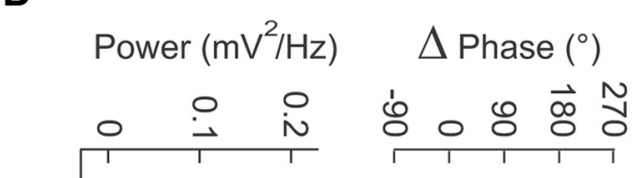

E
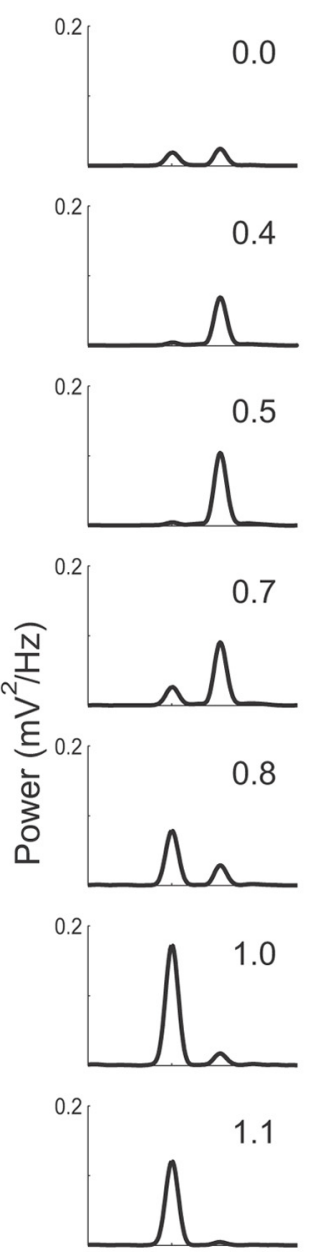

0.2

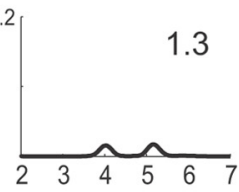

Frequency $(\mathrm{Hz})$

Figure 5. The amplitude and phase shift of $\theta$ and respiration-induced rhythm (HRR) differ across hippocampal layers. $\boldsymbol{A}$, Raw example traces from fissure (fis) and hilus (hil). B, C, Time-frequency analysis of respiration $(\boldsymbol{B})$ and LFPs simultaneously recorded from different depths of the $(A 1-$ dentate axis, as labeled ( $($ ). For better visualization, each plot has different power scales. $\boldsymbol{D}$, Peak power (left) and phase shift (right) for $\theta$ (black) and HRR (blue) across multiple sites of the CA1- dentate axis. Recordings were made using a 16-channel probe. For each probe channel, the phase difference was computed in relation to the phase of the most superficial electrode. $\boldsymbol{E}$, Power spectra with the same scaling for example probe sites. $\theta$ oscillations are maximal at the hippocampal fissure, whereas respiration-induced rhythms are maximal at the hilus. Further, both oscillations appear in approximately equal strength in sites away from their peak amplitude, both above (top) and below (bottom). g.c., Granule cell; pyr., pyramidal cell.

between the dorsal and ventral granule cell layers (Fig. 5D, right). These different and characteristic laminar profiles were consistently found in all animals $(n=8$; for group results and statistics, see Fig. 10) and suggest that different mechanisms underlie $\theta$ and respiration-induced oscillations.

Hippocampal neurons are differentially entrained by the respiration-induced rhythm and $\theta$ oscillations

Network oscillations are thought to provide a temporal reference signal for distributed neuronal ensembles. In support, neuronal discharges are frequently phase-coupled to the underlying rhythms (Buzsáki, 2002; Buzsáki and Draguhn, 2004). We next investigated whether the respiration-induced oscillations entrain hippocampal neurons. MUA was recorded from the principal cell layers of CA1 and DG with 16-channel silicon probes. Spike probability distributions in both hippocampal subfields were clearly modulated by both $\theta$ and HRR (Fig. 6A). Quantitative analysis revealed that the majority of MUA $(>73 \%)$ recorded in CA1 and DG of 12 mice was significantly phase-coupled with $\theta$ and HRR (Fig. $6 B$, right panel; $p<0.05$, Rayleigh test). For $\theta$ oscillations, coupling strength of MUA did not differ between CA1 and DG (Fig. 6B, left top). In contrast, HRR modulated DG units stronger than CA1 units (Fig. $6 B$, left bottom; $p<0.05$, Mann-Whitney $U$ test). Together, these data show that the respiration-induced oscillations entrain neuronal discharges in the hippocampus with strongest influence in DG. 
A

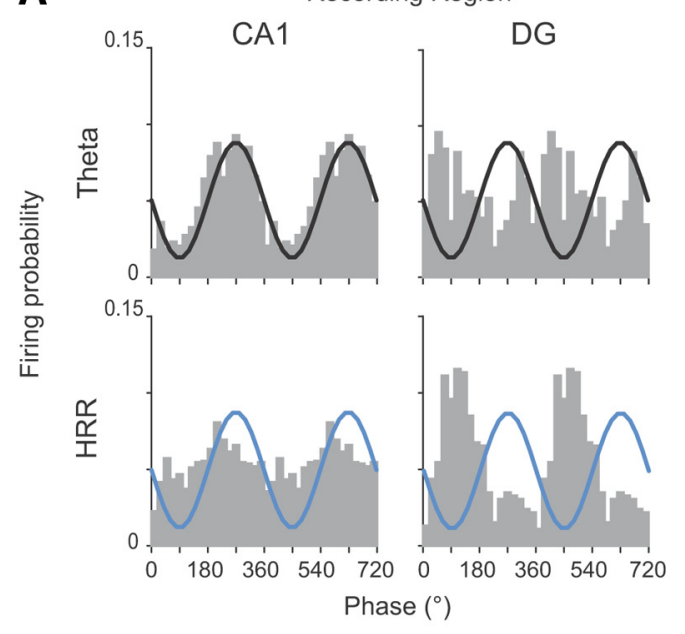

C
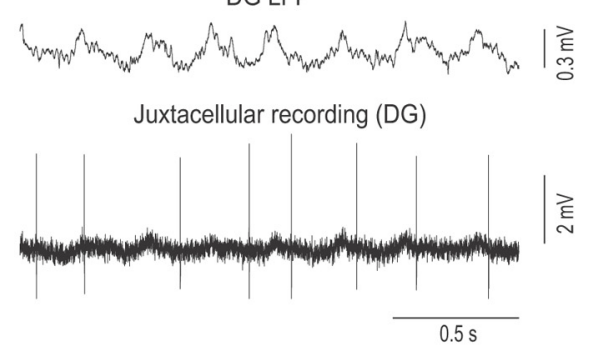

E

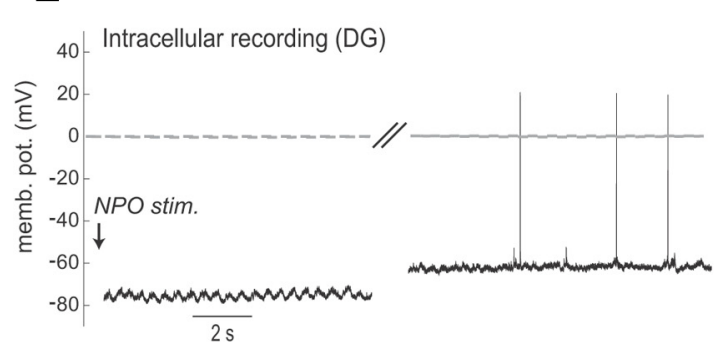

B
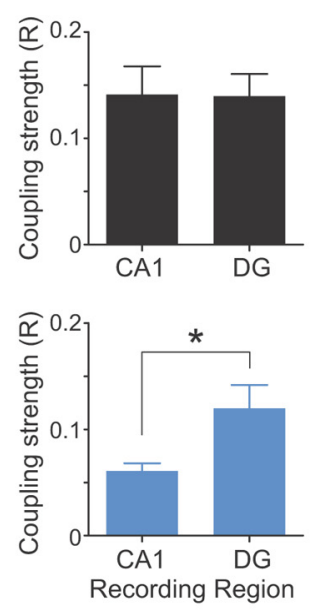

Theta
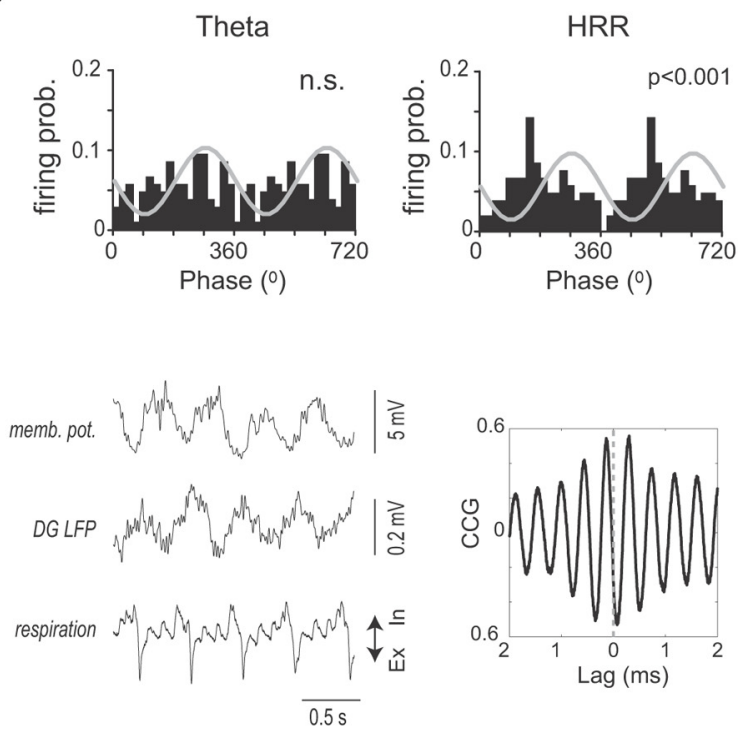

Figure 6. HRR modulates DG spiking activity and subthreshold membrane potentials. $\boldsymbol{A}$, Spike probability distribution as a function of the phase of hippocampal $\theta$ (top; recorded at the fissure) and HRR (bottom; recorded at the hilus) for an example of multiunit activity recorded from the CA1 pyramidal layer (left) and at the DG (right). 0scillation trough and peak corresponds to $90^{\circ}$ and $270^{\circ}$, respectively, as indicated by the reference sinusoids. $\boldsymbol{B}$, Left, Mean modulation strength of CA1 and DG multiunit activity by the hippocampal $\theta$ and HRR. Only significantly modulated spikes were taken into account. There is stronger modulation of DG than CA1 spikes by HRR phase: * $p<0.05$ (Mann-Whitney U test). Right, Percentage of multiunit activity significantly modulated by $\theta$ and HRR in CA1 and DG, as assessed by the Rayleigh test. $\boldsymbol{C}, \boldsymbol{D}$, LFP and juxtacellular recordings from a single cell in DG (C), along with the cell's spike distribution over the phases of $\theta$ and HRR (D). n.s., Not significant $\boldsymbol{E}$, Left, Intracellular recording of a DG neuron immediately after nucleus pontis oralis (NPO) stimulation (stim.) and after a short period with a diminished arousal level and sleep-like activity (right). Middle, Simultaneous recordings of membrane potential (memb. pot.), DG LFP, and respiration during a time period immediately after NPO stimulation. Right, Crosscorrelation (CCG) between membrane potential and DG LFP.

Recordings at cellular resolution revealed that single neurons in the DG could be selectively entrained by HRR. This is illustrated by the juxtacellular recording shown in Figure $6 C, D$, which shows clear modulation of a DG cell by HRR $(p<0.001$, Rayleigh test) but no entrainment by $\theta$. To study subthreshold effects of the hippocampal respiration-induced oscillations, we recorded intracellularly from neurons in the DG and CA1. In these recordings, arousal from sleep-like activity was induced by electrical stimulation of the brainstem (see Materials and Methods), as previously described (McNaughton et al., 2007). Recordings from seven putatively principal DG neurons revealed variable effects of brainstem stimulation (depolarization in 4 neurons, hyperpolarization in 2 cells, and no visible membrane potential change in the remaining cell). Interestingly, three neurons exhibited subthreshold membrane potential oscillations after brainstem stimulation (for an example, see Fig. $6 E$, left). This oscillation was highly coherent and in antiphase with the LFP respiration-induced oscillation (Fig. 6E, middle and right). In contrast, none of seven putatively principal CA1 neurons revealed visible respiratory oscillations at the subthreshold level upon brainstem stimulation, despite clear shifts of membrane potential in 3 cells (data not shown).

Thus, intracellular recordings suggest a selective subthreshold modulation of DG neurons by HRR. Evoked field potential responses were consistent with these findings: electrical stimulation of the lateral olfactory tract (LOT) led to current sinks in the molecular layer of the DG and sources in the granule cell layers and hilus ( $n=4$ mice, see Fig. $7 A$ ). This behavior is in line with synaptic inputs carrying $\mathrm{OB}$ information from the lateral entorhinal cortex to the dendrites of DG neurons (Canning et al., 2006). Accordingly, the peak latency of synaptic potentials in DG 
A Perforant Path Stimulation

\section{Olfactory Tract Stimulation}

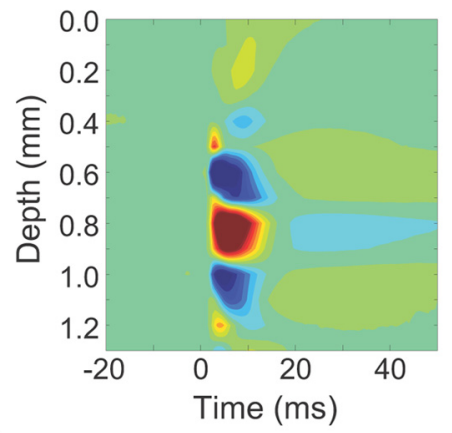

B

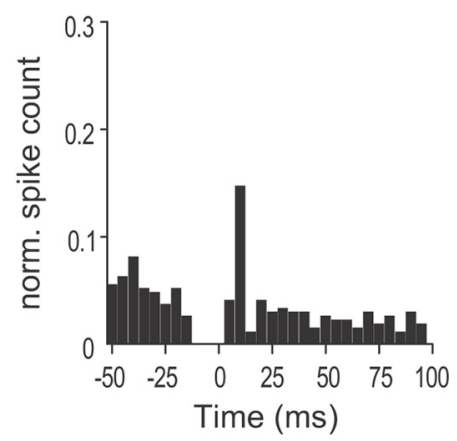

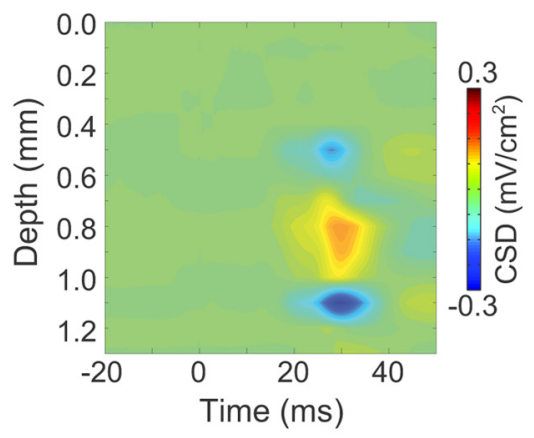

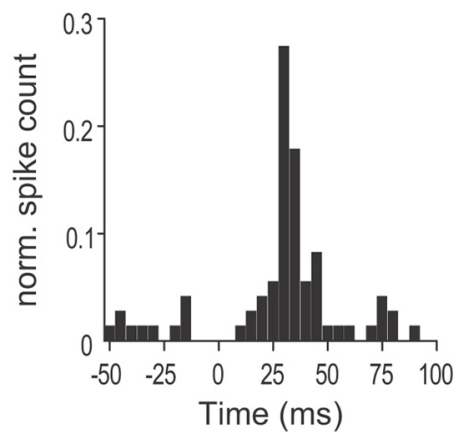

Figure 7. Electrical stimulation of the LOT leads to current sinks in the outer molecular layer of the DG. $A$, Current source density (CSD) maps computed from responses across the CA1-DG depth following perforant path (left) and LOT stimulation (right). $\boldsymbol{B}$, Perievent histograms (bin size: $5 \mathrm{~ms}$ ) of multiunit activity triggered by perforant path (left) and LOT stimulation (right).

was longer for LOT stimulation than for perforant path stimulation (group data: $27.0 \pm 2.9 \mathrm{~ms}$ compared with $5.8 \pm 0.1 \mathrm{~ms} ; p<$ 0.01 , paired $t$ test). Similar latencies were found for increased spike counts after stimulation of LOT or the perforant path (see Fig. $7 B$ ). Together, our results show that the hippocampal respiration-induced oscillations modulate neuronal activity at both the subthreshold and suprathreshold levels and are most likely transferred from the $\mathrm{OB}$ via the lateral olfactory path and the lateral entorhinal cortex.

\section{The hippocampal respiration-induced rhythm is resistant to atropine}

Atropine is known to abolish $\theta$ oscillations in urethaneanesthetized rodents (Kramis et al., 1975). We therefore investigated whether the hippocampal respiration-induced oscillations share this pharmacological feature. In 4 of 6 animals treated with atropine $(50 \mathrm{mg} / \mathrm{kg}$ i.p.), we were able to induce a clear arousal reaction that was consistently accompanied by HRR. At the same time, $\theta$ activity in the hippocampus was disrupted by the cholinergic antagonist (Fig. $8 A, B$ ). Atropine decreased respiration rate $(\sim 4 \mathrm{~Hz}$ to $\sim 3 \mathrm{~Hz})$, which was exactly followed by HRR frequency (Fig. 8B). Importantly, HRR amplitude was not changed by atropine, showing its independence of muscarinic receptor activation, in clear contrast to atropine-sensitive $\theta$ oscillations.

This result was corroborated by comparing laminar profiles for both rhythms in the absence and presence of atropine. The position of 16-channel electrodes along the CA1-DG axis was confirmed by stimulating the perforant pathway (see Materials and Methods; Fig. $8 C$ ). $\theta$ oscillations showed the typical phase reversal across the CA1 pyramidal cell layer and maximal amplitude at the hippocampal fissure (Fig. 8D, top left) (Brankačk et al., 1993). Whereas responses to perforant path stimulation were not changed by atropine (Fig. $8 C$ ), $\theta$ oscillations at the fissure were largely abolished (Fig. 8D; for group results, see Fig. $10 B: 0.19 \pm 0.03, n=8$ vs $0.03 \pm 0.01, n=$ 4 after atropine; $p<0.01, t$ test). In strong contrast, HRR at the hilus was preserved (and even more pronounced in some animals) after injection of atropine $(0.16 \pm$ $0.03, n=8$ vs $0.12 \pm 0.03, n=4$ after atropine; $p=0.44, t$ test). Figure $8 E$ shows the corresponding CSD plots. In summary, atropine disrupts $\theta$-entrained current sinks and sources in the CA1 region but leaves HRR in the DG intact.

\section{Tracheotomy abolishes the hippocampal respiration-induced rhythm but not $\boldsymbol{\theta}$}

As stated above, the synchrony between the slower hippocampal oscillation, respiratory activity, and the $\mathrm{OB}$ field potentials led us to call this network pattern "hippocampal respiration-induced rhythm." We hypothesized that there are at least two possible sources of this oscillation: it may arise from respiration-coupled nasal inputs or, alternatively, from activity of the brainstem respiratory pattern generator (Moore et al., 2013; Smith et al., 2013). To assess the relationship between respiration, nasal input, and the hippocampal oscillation, we bypassed nasal airflow through tracheotomy $(n=$ 6 mice; Fig. 9). Spontaneous respiration was maintained in these animals (Fig. 9A-C), indicating that this method distinguishes between brainstem-driven respiration and inputs induced by nasal airflow. Tracheotomy consistently abolished HRR (control mean amplitude: $0.16 \pm 0.03 \mathrm{mV}, n=8$ vs $0.03 \pm 0.01, n=6$ after tracheotomy, $p<0.01, t$ test). In contrast, $\theta$ oscillations continued largely unchanged $(0.19 \pm 0.03 \mathrm{mV}, n=8$ vs $0.14 \pm$ $0.02, n=6 ; p=0.22, t$ test), although at somewhat slower frequency (Fig. $9 A, B, D$; compare with Figs. $1 C, 5 E$, and $8 B$ ). In six animals, we also recorded LFP from the OB, which were likewise abolished after bypassing nasal respiration (Fig. 9C; group mean control: $0.12 \pm 0.03, n=6$; group mean tracheotomy: $0.01 \pm$ $0.001, n=4 ; p<0.05, t$ test) (Fontanini et al., 2003). Similar to mice with normal nasal airflow, application of atropine suppressed hippocampal $\theta$ oscillations in tracheotomized mice (Fig. 9A, B,D; tracheotomy: $0.14 \pm 0.02 \mathrm{mV}, n=5$ vs tracheotomy + atropine: $0.02 \pm 0.01 \mathrm{mV}, n=4 ; p<0.001, t$ test). Respiration-related oscillations in $\mathrm{OB}$ of normally breathing mice are also resistant toward atropine, similar to HRR (Fig. 9C, bottom left). Thus, the respiration-induced hippocampal oscillation is clearly driven by sensory inputs resulting from airflow through the nose. Figure 10 summarizes the main results of these experiments.

\section{Relationship between hippocampal respiration-induced rhythm and $\gamma$ oscillations}

In addition to the nasal respiration-induced oscillations in the near- $\theta$ range, the DG expresses prominent rhythms at $\gamma$ frequency $(30-100 \mathrm{~Hz})$ (Bragin et al., 1995). Previous studies have shown that olfactory inputs elicit bursts of $\gamma$ oscillations in the DG (Vanderwolf, 1992, 2001). Interestingly, we found that the laminar profile of $\gamma$ oscillations across the CA1-DG axis was 
A

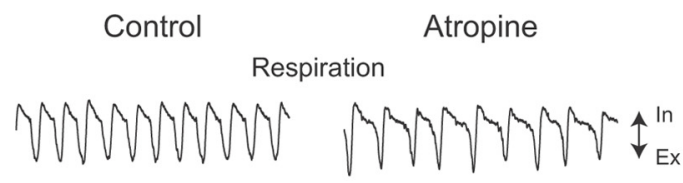

Fissure LFP

Whinewhonin

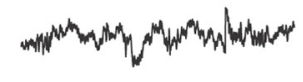

Hilus LFP
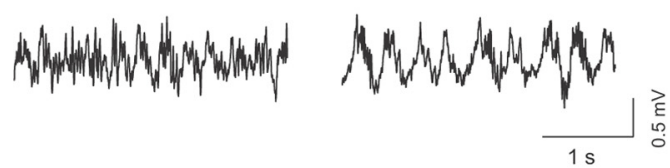

B
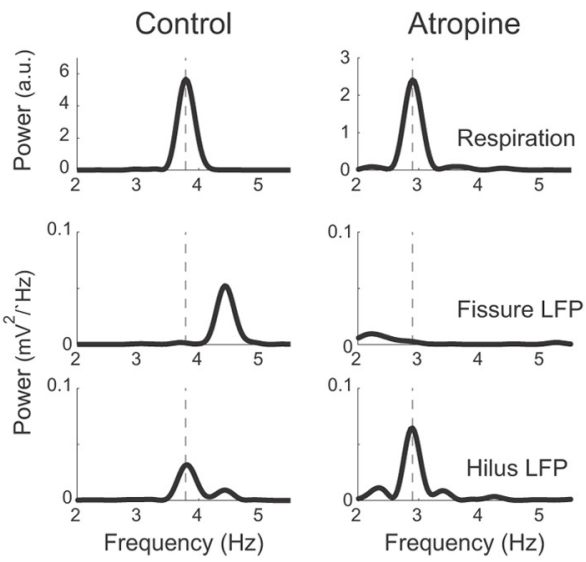

C

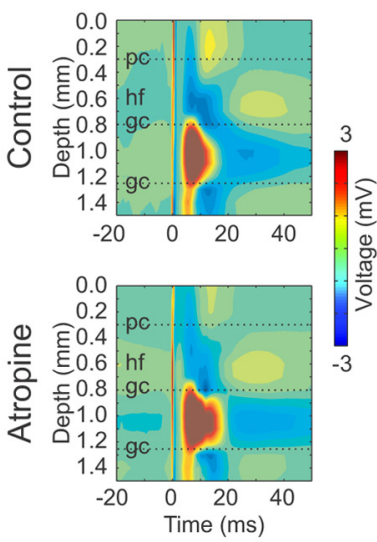

D Theta
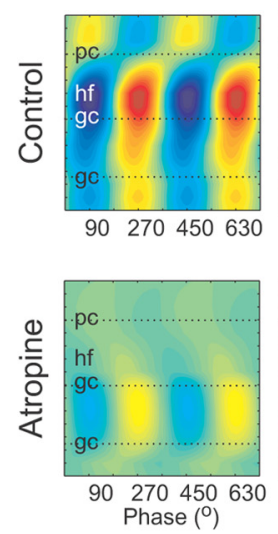

HRR

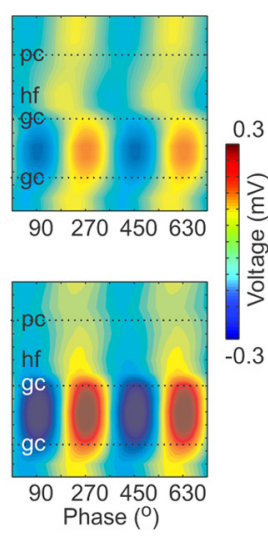

E
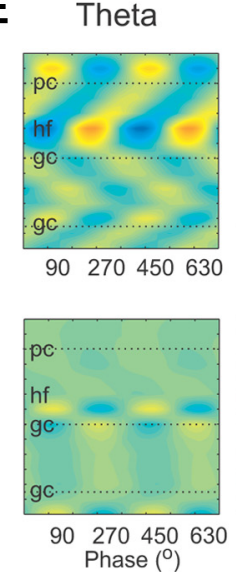

HRR

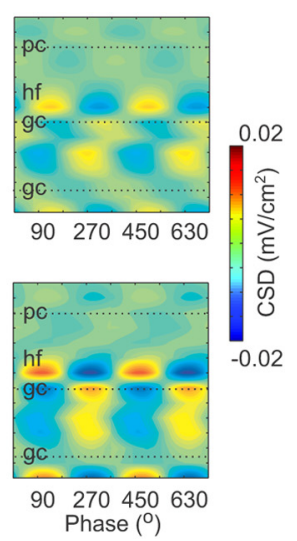

Figure 8. Atropine disrupts $\theta$ but not HRR in the hippocampus. $A$, Representative traces of respiratory activity (top) and LFP signals simultaneously recorded from the hippocampal fissure (middle) and hilus (bottom) before (left) and after atropine (right). $\boldsymbol{B}$, Power spectra of the same signals as in $\boldsymbol{A}$. Dashed lines indicate peak respiration frequency. $\boldsymbol{A}, \boldsymbol{B}$, Atropine abolishes $\theta$ oscillations at the hippocampal fissure (hf) and preserves HRR at the hilus. C, Voltage changes across the CA1-dentate axis upon perforant path (PP) stimulation (Stim.) showing similar profile under control conditions (top) and after atropine (bottom). These responses were used to assess probe location and identify the anatomical landmarks. $\boldsymbol{D}, \boldsymbol{E}$, Voltage depth profile (D) and current source density $(\boldsymbol{E})$ analysis of $\theta$ and HRR before (top) and after atropine (bottom). pc, Pyramidal cell; gc, granule cell.

very similar to the laminar profile of HRR, with maxima for both patterns in the dentate hilus (Fig. 11A).

Nesting of $\gamma$ oscillations within $\theta$ cycles is a prominent feature of hippocampal networks (Chrobak and Buzsáki, 1998; Tort et al., 2009; Colgin and Moser, 2010; Scheffer-Teixeira et al., 2012; Lisman and Jensen, 2013). Does HRR also modulate $\gamma$ oscillations in the hippocampus?

We constructed averaged heat maps of the amplitude of fast oscillations $(20-200 \mathrm{~Hz})$ triggered by the troughs of $\theta$ or $\operatorname{HRR}(n=11$; Fig. $11 B$, left). We found that $\gamma$ amplitude was modulated by the phase of both slow oscillations. However, the frequency range of $\gamma$ oscillations modulated by HRR was larger than by $\theta$ (Fig. $11 B$ ). We further corroborated these results by analyzing phase-amplitude distributions and computing associated modulation indexes (see Material and Methods), which showed that, on the group level, $\theta$ preferentially modulated low $\gamma$, whereas HRR modulated the whole $\gamma$ band (Fig. 11C). Interestingly, however, in some animals, HRR specifically modulated high, but not low, $\gamma$ amplitude (Fig. $11 D, E$ ). Of note, $\gamma$ nesting into $\theta$ or HRR phase was visible in raw and filtered traces (Fig. 11D). Coupling of the whole $\gamma$ band $(30-100 \mathrm{~Hz})$ by the HRR occurred at a significantly $(n=11 ; p<0.001$, Watson-Williams test) different phase (mean angle: $259.5^{\circ}, \mathrm{SD}: 25.5^{\circ}$ ) compared with $\theta$ - $\gamma$ coupling (mean angle: $30.2^{\circ}$, SD: $9.6^{\circ}$, Fig. $11 F$ ). Thus, the preferred phase and frequency range of coupled $\gamma$ oscillations are different between $\theta$ and HRR.
In all, our results show that $\theta$ and respiration-induced oscillations have different depth distribution in the hippocampus, different sensitivity to cholinergic blockers, different dependence on nasal airflow, and different coupling to $\gamma$ oscillations.

\section{Discussion}

Here we reported a new pattern of network oscillations between 2 and $4 \mathrm{~Hz}$ in the mouse hippocampus. This slow oscillation synchronizes hippocampal networks with nasal respiration and with the well-known respiration-entrained field potentials in the $\mathrm{OB}$ (Adrian, 1942; Freeman, 1978; Fontanini et al., 2003). The respiration-induced rhythm modulates subthreshold membrane oscillations and neuronal discharges in the hippocampus. Importantly, several lines of evidence show that the hippocampal respirationinduced rhythm is clearly distinct from $\theta$ oscillations. Together, our findings suggest that $\theta$ and respiration-induced oscillations play different roles in hippocampal information processing.

\section{Respiration-induced rhythms propagate to the hippocampal formation}

Respiration-entrained oscillations in the OB have first been described by Adrian (1942, 1950). Consistent with our findings, previous work demonstrated that OB rhythms disappear after bypassing nasal airflow through tracheotomy, which shows that they are generated by peripheral stimuli as opposed to central 
A

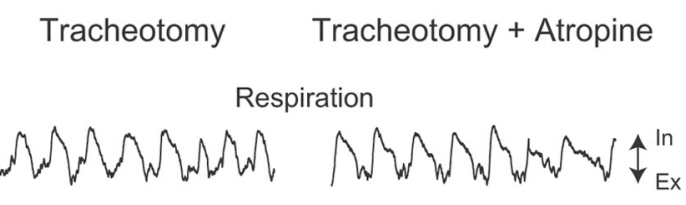

WWMMMMMn

Fissure LFP

Hilus LFP
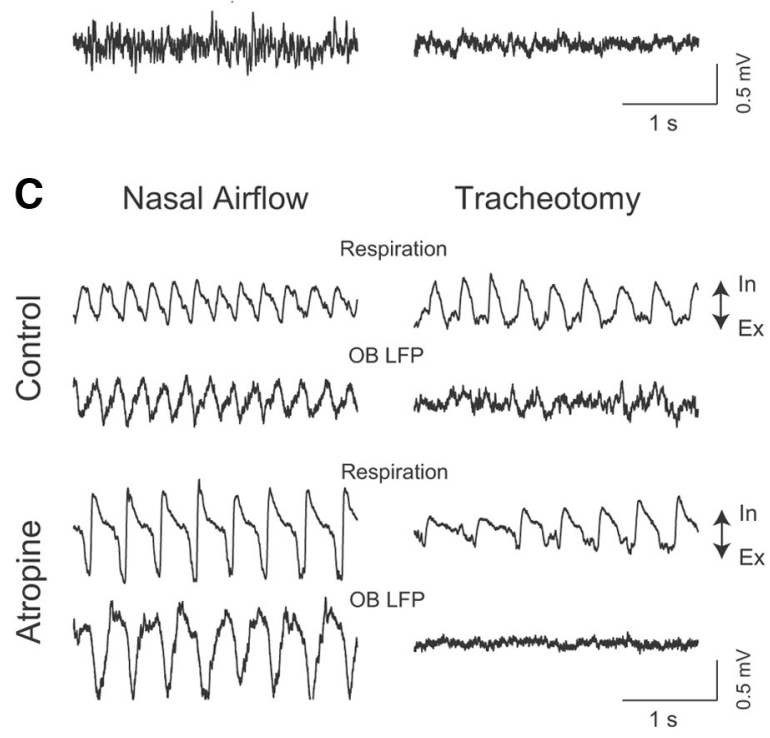

B

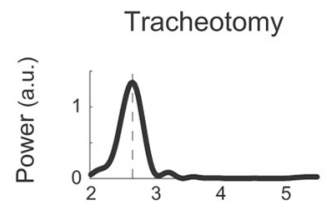

Tracheotomy + Atropine
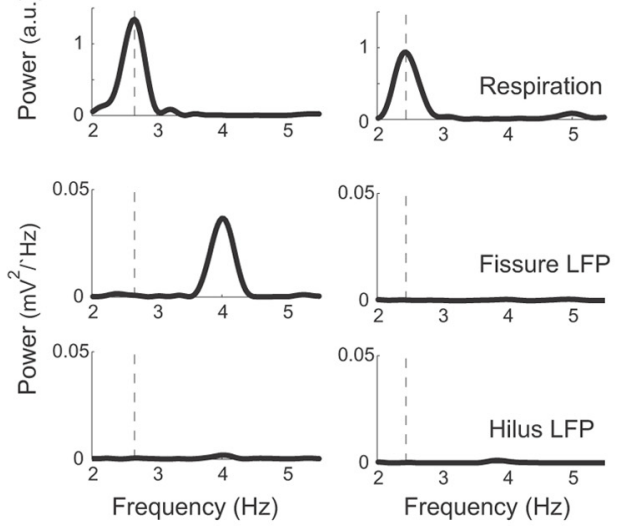

D
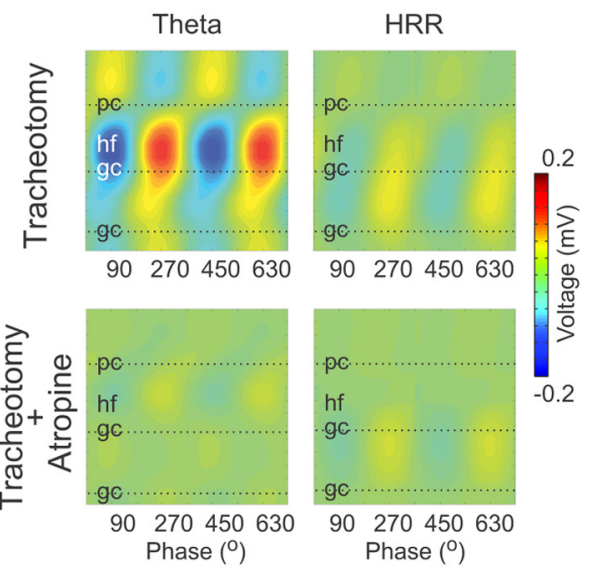

Figure 9. Tracheotomy abolishes olfactory bulb oscillations and HRR, but not $\theta$ oscillations. $\boldsymbol{A}$, Representative traces of respiratory activity (top) and LFP signals simultaneously recorded from the hippocampal fissure (middle) and hilus (bottom) before and after atropine in an animal with bypassed nasal airflow through tracheotomy. $\boldsymbol{B}$, Power spectra of the same signals as in $\boldsymbol{A}$. Dashed lines indicate peak respiration frequency. Tracheotomy abolishes the HRR at the hilus and preserves $\theta$ oscillations at the fissure, which are sensitive to atropine. $C$, Representative traces of respiration and LFP signals simultaneously recorded from the OB in mice with (right) and without (left) tracheotomy and before (top) and after atropine (bottom). $D$, Voltage depth profile of $\theta$ and HRR in tracheotomized mice before (top) and after atropine (bottom). In, Inspiration; Ex, expiration.

respiratory networks (Fontanini et al., 2003). Further studies suggested that the relevant stimulus for slow $\mathrm{OB}$ oscillations is nasal airflow rather than specific odor stimuli: indeed, olfactory sensory neurons do react to mechanical stimulation by odorless airflow (Grosmaitre et al., 2007). The resulting network oscillation in the $\mathrm{OB}$ propagates to closely related areas, such as the piriform (olfactory) cortex where it induces rhythmic activity in LFP and intracellular potentials (Fontanini et al., 2003; Wesson et al., 2011). The present work shows a new long-range effect of respiratory oscillations: the generation of prominent network oscillations in hippocampal networks. It is thus likely that these oscillations contribute to polymodal sensory integration in this area.

\section{Hippocampal respiration-induced rhythm and $\boldsymbol{\theta}$ oscillations are distinct despite overlapping frequency ranges}

The frequency of hippocampal respiration-induced oscillations in mice is close to the lower frequency boundary of $\theta$ oscillations, which may impede their unambiguous identification in recordings of spontaneous field potential activity. Basal respiration frequency differs strongly between species: rats, for example, have basal respiration rates of $\sim 1$ to $1.5 \mathrm{~Hz}$ at rest (Crosfill and Widdicombe, 1961; Carnevali et al., 2013). Respiration-driven rhythms in these animals, as present in the olfactory system, must therefore be distinguished from slow oscillations known as "up and down-states" (Steriade et al., 1993; Fontanini et al., 2003). Urethane-anesthetized mice breathe at 2-4 Hz (Crosfill and Widdicombe, 1961; Depuy et al., 2011), whereas $\theta$ oscillations in urethane-anesthetized rodents are centered $\sim 4-6 \mathrm{~Hz}$ (Kramis et al., 1975). In our study, the frequency distribution of respirationinduced oscillations exhibited an overlap with the lower end of the $\theta$ frequency range (Fig. 2). This similarity has already been noted for olfaction-related rhythms within the OB, which has been termed "olfactory $\theta$ " (Margrie and Schaefer, 2003; for review, see Kay et al., 2009). However, despite the overlapping frequency ranges, our results argue against any mechanistic similarity between both rhythms: (1) the $2-4 \mathrm{~Hz}$ basal respirationinduced rhythm depends on nasal airflow, whereas $\theta$ oscillations do not; (2) the respiration-induced rhythm is not suppressed by atropine, in contrast to urethane-induced $\theta$ (Kramis et al., 1975; Buzsáki et al., 1986); (3) both oscillations have clearly different laminar profiles across the CA1-DG axis; (4) neurons in DG are differentially entrained by both rhythms; (5) both rhythms differentially modulate $\gamma$ oscillations; and (6) there is no correlation between the power of both rhythms. We therefore conclude that hippocampal respiration-induced oscillations represent a unique network pattern.

The particular layered organization of the hippocampus allows distinguishing different synaptic inputs by their characteristic laminar profile (Winson, 1976; Buzsáki et al., 1986; Ylinen et 
A
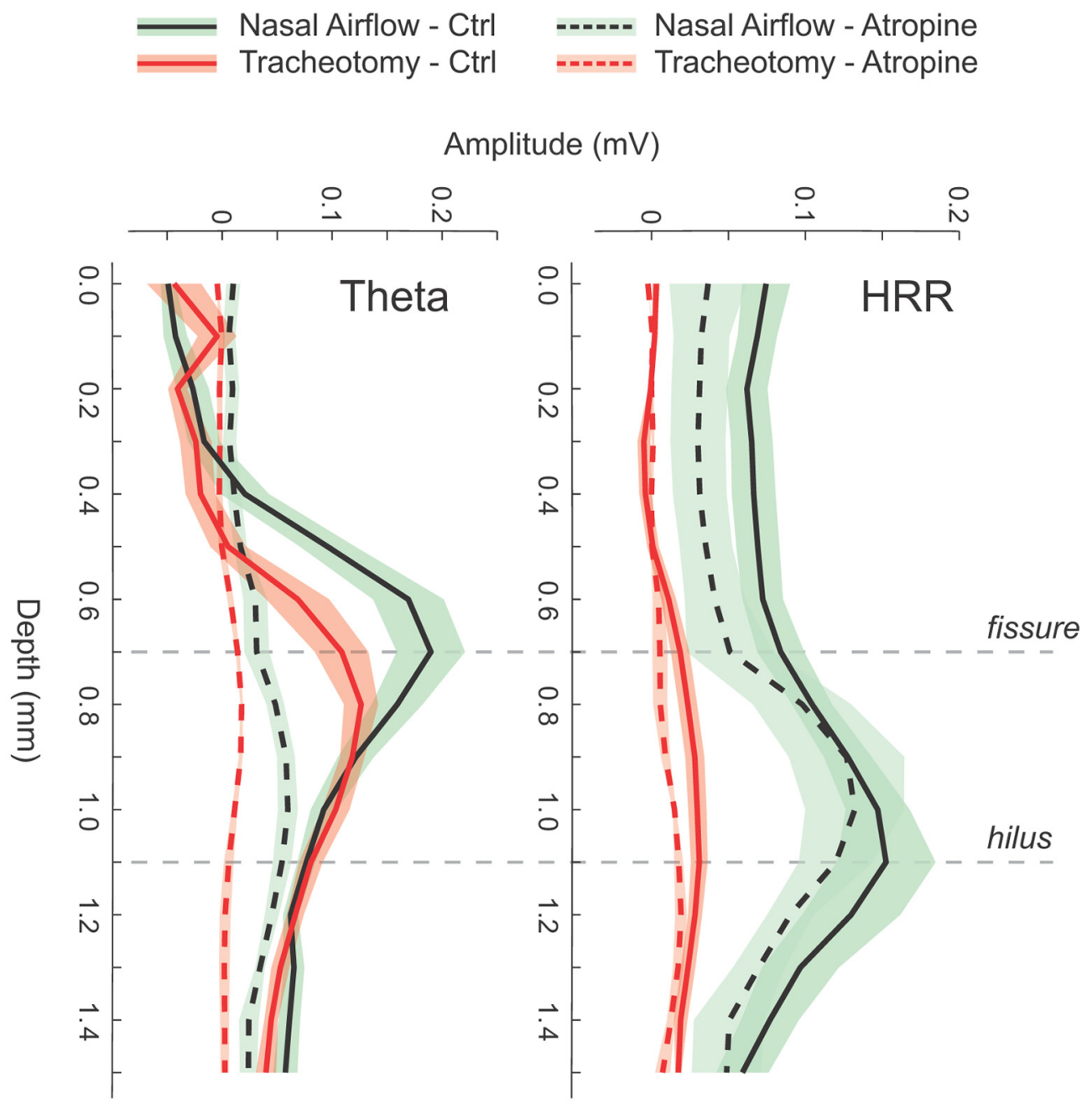

B

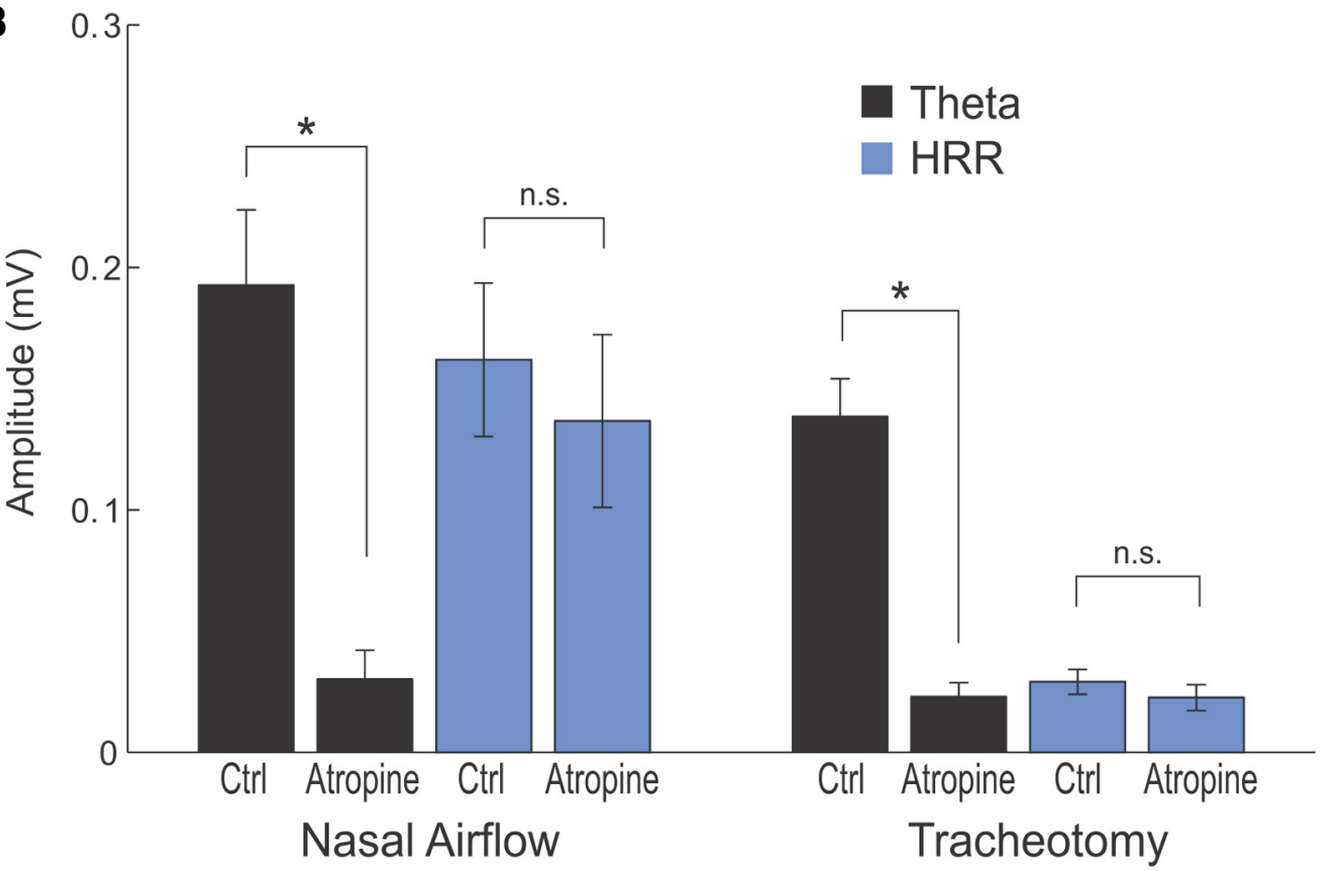

Figure 10. HRR and $\theta$ oscillations have different depth profiles, sensitivity to atropine, and dependence on nasal airflow (group results). $\boldsymbol{A}$, Solid lines indicate mean voltage depth distribution of $\theta$ and HRR in mice with (red shade, $n=6$ ) and without tracheotomy (green shade, $n=8$ ). Ctrl, Control. Dashed black lines indicate the effect of atropine in each condition ( $n=4$ ). Shades represent \pm SEM. $B$, Mean amplitude of $\theta$ and HRR recorded at the hippocampal fissure and hilus, respectively, for the different experimental conditions. Error bars indicate SEM. Atropine significantly abolishes $\theta$ ( $n=8 \mathrm{vs} n=4$; ${ }^{*} p<0.01$, $t$ test) but does not affect HRR. Tracheotomy abolishes HRR ( $n=8 \mathrm{vs} n=6,{ }^{*} p<0.01, t$ test) but does not alter $\theta$. n.s., Not significant. 
A

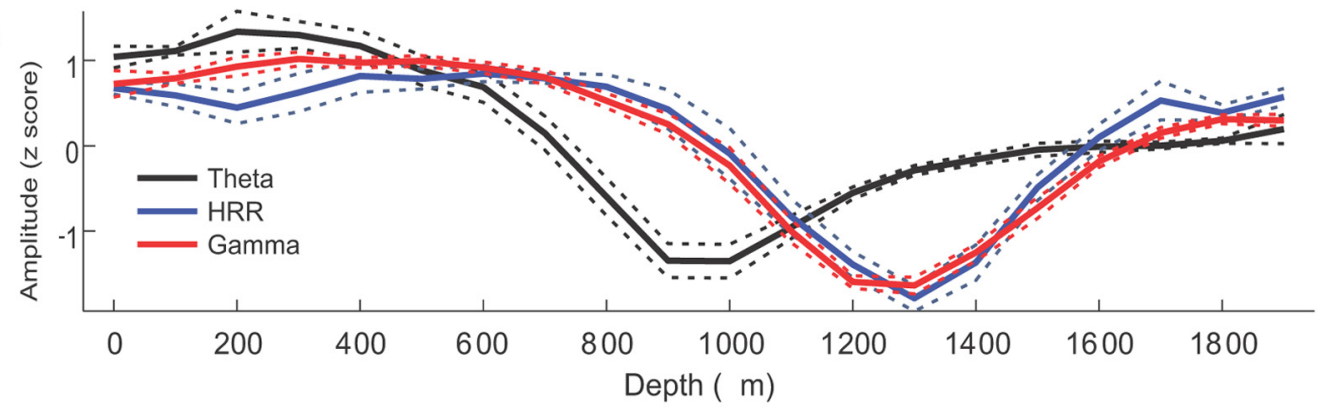

B

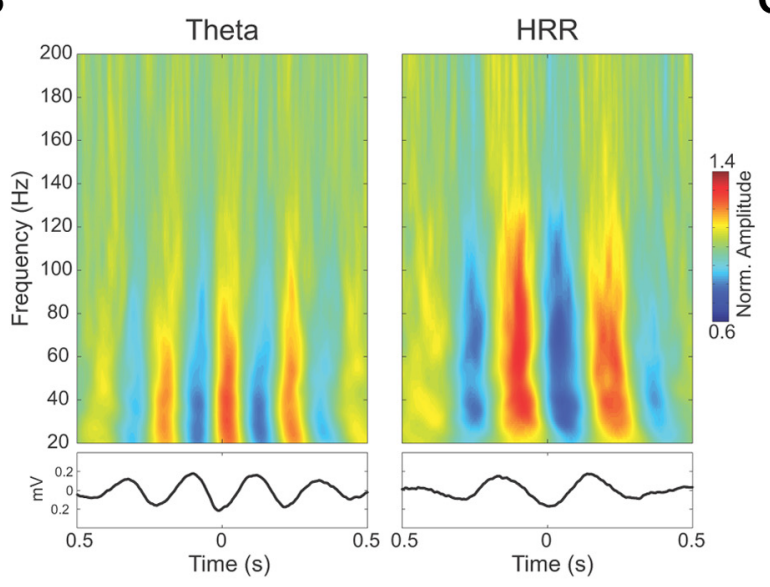

D

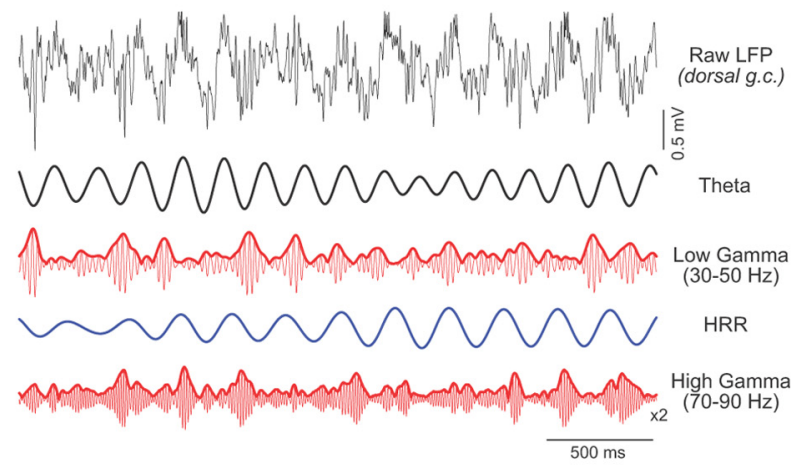

$\mathbf{F}$

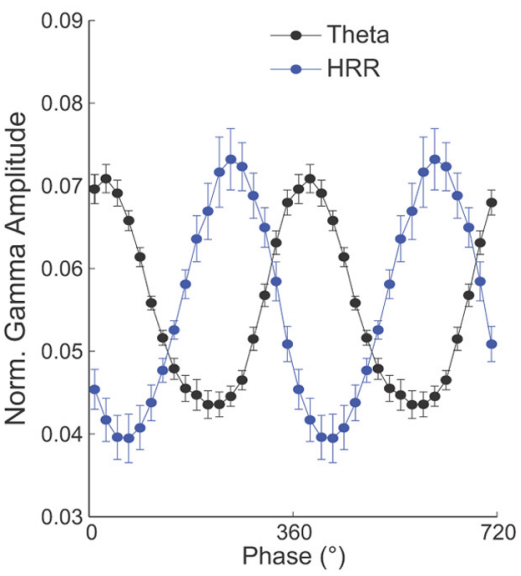

C
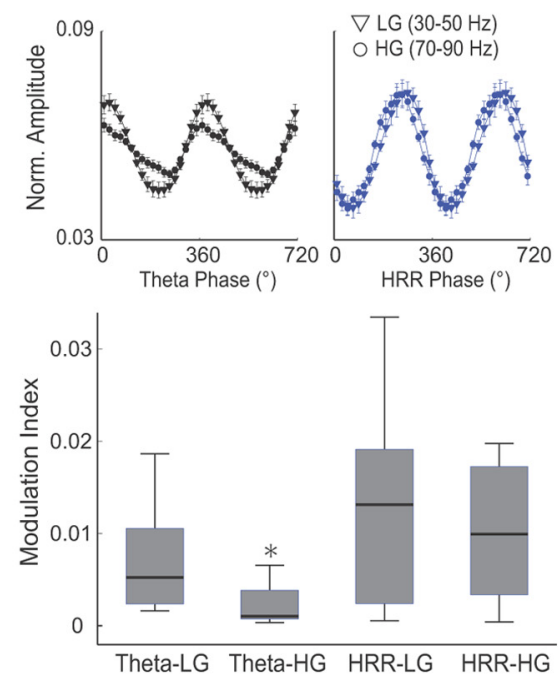

E
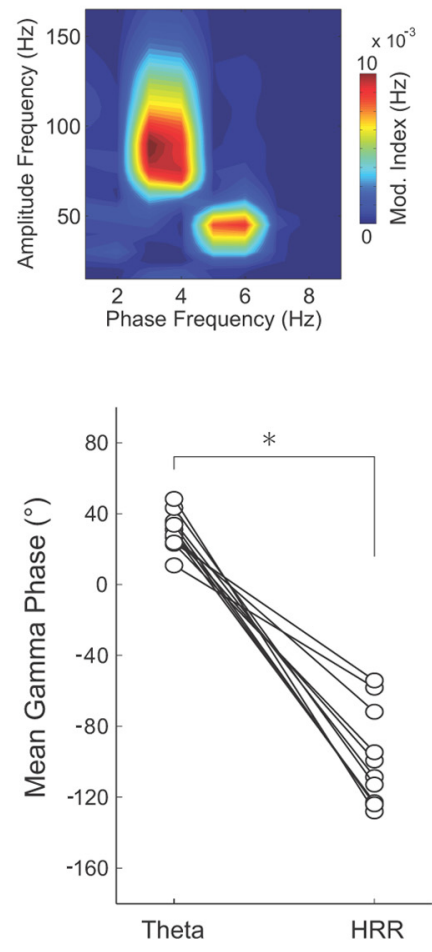

Figure 11. $\theta$ and HRR differentially modulate $\gamma$ oscillations. $A$, Mean $\pm \operatorname{SEM}(n=8)$ laminar profile of the amplitude of $\gamma$ oscillations (red) along with $\theta$ (black) and HRR (blue). Amplitude values were $z$-scored to allow plotting in the same scale. There are similar laminar profiles between $\gamma$ and HRR. $\boldsymbol{B}$, Average heat maps $(n=11)$ showing the amplitude of hippocampal fast oscillations triggered by the troughs of $\theta$ phase or HRR, as labeled. To correct for 1/f, amplitudes were normalized within frequencies by dividing by the mean amplitude (see Materials and Methods). Bottom panels, Trough-locked averages of unfiltered LFPs. HRR modulates a wider range of $\gamma$ frequencies. C, Top panels, Mean amplitude for low (LG, $30-50 \mathrm{~Hz})$ or high ( $\mathrm{HG}, 70-90 \mathrm{~Hz}) \gamma$ as a function of the phase of $\theta$ (left) or HRR (right). For each animal, the mean amplitude in each phase bin was normalized by dividing by the sum over all bins (Tort et al., 2010). Trough is at $360^{\circ}$. Two cycles are plotted for clarity. Bottom panel, Boxplot distributions for coupling strength (modulation index, see Materials and Methods) between $\theta$ or HRR phase and (Figure legend continues.) 
al., 1995a; Buzsáki, 2002). In our recordings, $\theta$ oscillations reversed across the pyramidal cell layer and reached maximal power at the hippocampal fissure (Bland and Whishaw, 1976; Buzsáki et al., 1986; Brankačk et al., 1993). The underlying current sinks and sources (Nicholson and Freeman, 1975; Mitzdorf, 1985) were mainly restricted to the CA1 region and the hippocampal fissure, consistent with previous findings (Buzsáki et al., 1986; Brankačk et al., 1993). Slow respiration-driven oscillations showed a strikingly different distribution: the amplitude did not reverse polarity across the pyramidal cell layer but gradually increased with increasing depth, reaching maximal value at the hilus. The corresponding current source density analysis showed pronounced sinks covering the entire molecular layers of the DG, as well as sources within the granule cell layers. These distinct profiles show that $\theta$ and respiration-driven oscillations are driven by different synaptic inputs.

Notably, stimulation of the perforant path activated similar sinks in the molecular layer as the respiration-driven oscillation (Fig. 8). This similarity indicates a role for excitatory inputs from layer II of the entorhinal cortex to the molecular layer of the DG (Steward and Scoville, 1976; Witter and Groenewegen, 1984). Indeed, the lateral entorhinal cortex receives strong synaptic input from olfactory networks, constituting a direct link to the hippocampal formation. A monosynaptic input to the entorhinal cortex comes from mitral cells of the OB via the LOT (Haberly and Price, 1977; Kosel et al., 1981; Wouterlood and Nederlof, 1983; Schwerdtfeger et al., 1990), and an additional, disynaptic input connects the $\mathrm{OB}$ via the piriform cortex to the same neurons (Witter et al., 1989; Burwell and Amaral, 1998). In our experiments, stimulation of the LOT induced a laminar profile consistent with the lateral entorhinal input (compare left and right panels in Fig. 7A), and strongly similar to the hippocampal respiration-induced rhythm. It is thus likely that respirationdriven oscillations in the hippocampus are generated by synaptic inputs from the $\mathrm{OB}$ or piriform cortex via the lateral entorhinal cortex (Witter and Groenewegen, 1984; Canning et al., 2006). In agreement with this, DG neurons exhibited stronger phasecoupling to respiration-induced oscillations than CA1 neurons.

\section{Functional considerations}

What are the possible functions of the respiration-induced rhythm in the hippocampal formation? The hippocampus receives polymodal sensory inputs from the entorhinal cortex (Brankačk and Buzsáki, 1986). Mice and other rodents are strongly dependent on olfactory cues, and neurons in the lateral entorhinal cortex respond to odor stimuli ( $\mathrm{Xu}$ and Wilson, 2012). Numerous studies have shown that the flow of olfactory information along the entorhinal-DG pathway is important for olfactory learning and memory formation (Staubli et al., 1984, 1986; Otto and Eichenbaum, 1992; Kaut et al., 2003; Martin et al.,

\footnotetext{
$\leftarrow$

(Figure legend continued.) $\quad \mathrm{LG}$ or $\mathrm{HG}$ amplitude. $\theta-\mathrm{HG}$ coupling strength was significantly lower than $\theta-\mathrm{LG}, \mathrm{HRR}-\mathrm{LG}$, and HRR-HG coupling: ${ }^{*} p<0.005$ (Friedman test). D, Representative raw $L F P$ trace plotted along with $\theta$-, HRR-, LG-, and HG-filtered signals, as labeled. There are prominent variations in the amplitude of $L G$ and $H G$ depending on the instantaneous phase of the slower rhythms. The HG-filtered trace was magnified by a factor of 2 for better visualization. $\boldsymbol{E}$, Comodulation map for the example shown in $\boldsymbol{D}$. There is prominent HRR-HG coupling along with $\theta$-LG coupling. F, Left, Mean $\gamma(30-100 \mathrm{~Hz})$ amplitude according to the phase of $\theta$ (black) and HRR (blue). $\gamma$ coupling occurs at different phases of $\theta$ and HRR. Middle, Distributions of the mean phase of maximal $\gamma$ amplitude. Top panel, Individual samples $(n=11)$. Bottom two panels, Circular histograms. Right, Same data points as in middle top panel plotted side by side ( $n=11 ; p<0.001$, Watson-Williams test).
}

2006). Our results suggest that slow, respiration-entrained neuronal oscillations play a role in the transfer of olfactory information to the hippocampus.

Despite the well-known anatomical connections, little is still known about the impact of olfactory inputs on hippocampal network activity. The $\mathrm{OB}$ also produces pronounced fast network oscillations, including $\beta$ and $\gamma$ frequencies (Bressler and Freeman, 1980; Kay et al., 2009). Interestingly, olfactory stimuli induce bursts of $15-80 \mathrm{~Hz}$ waves in the DG hilus, but not in CA1 (Vanderwolf, 1992; Vanderwolf, 2001). This topology corresponds to the laminar profile of the slow hippocampal respiration-induced oscillations described here (Fig. 11A). Slower oscillatory patterns have also been reported for the OB during both basal respiration and sniffing (Kay, 2005; see also Fujisawa and Buzsáki, 2011). Interestingly, previous studies involving sniffing-related cognitive tasks reported transient synchrony between hippocampal $\theta$ oscillations and the OB rhythm, as well as synchrony with sniffing activity (Macrides, 1975; Macrides et al., 1982; Eichenbaum et al., 1987; Vanderwolf, 1992; Kay, 2005). Our present results suggest that sniffing rather synchronizes distant cortical regions by a distinct oscillation pattern than $\theta$. However, the distinction between $\theta$ and respiration-induced oscillations may be even more difficult in nonanesthetized mice during sniffing behavior where olfactory rhythms in the $\mathrm{OB}$ can reach up to $12 \mathrm{~Hz}$ (Kay et al., 2009). Our experiments, in contrast, have been conducted in anesthetized mice breathing at $\sim 2-4 \mathrm{~Hz}$ during rest (Depuy et al., 2011), which allowed for a clear separation between respiration-induced oscillations and $\theta$.

In conclusion, we report an independent type of slow $(2-4 \mathrm{~Hz})$ respiration-induced hippocampal network oscillations in mice. The pattern is highly coherent with the basal respiration-induced rhythm in the $\mathrm{OB}$, and is likely to propagate from olfactory networks via the lateral entorhinal cortex to the dentate area, where it modulates neuronal activity. We hypothesize that the hippocampal respirationinduced oscillations contribute to odor information processing in the entorhinal-hippocampal network.

\section{References}

Adrian ED (1942) Olfactory reactions in the brain of the hedgehog. J Physiol 100:459-473. Medline

Adrian ED (1950) The electrical activity of the mammalian olfactory bulb. Electroencephalogr Clin Neurophysiol 2:377-388. CrossRef Medline

Alvarez P, Wendelken L, Eichenbaum H (2002) Hippocampal formation lesions impair performance in an odor-odor association task independently of spatial context. Neurobiol Learn Mem 78:470-476. CrossRef Medline

Bland BH, Whishaw IQ (1976) Generators and topography of hippocampal $\theta$ (RSA) in the anaesthetized and freely moving rat. Brain Res 118:259 280. CrossRef Medline

Bragin A, Jandó G, Nádasdy Z, Hetke J, Wise K, Buzsáki G (1995) $\gamma(40-100$ $\mathrm{Hz}$ ) oscillation in the hippocampus of the behaving rat. J Neurosci 15:4760. Medline

Brankačk J, Buzsáki G (1986) Hippocampal responses evoked by tooth pulp and acoustic stimulation: depth profiles and effect of behavior. Brain Res 378:303-314. CrossRef Medline

Brankačk J, Stewart M, Fox SE (1993) Current source density analysis of the hippocampal $\theta$ rhythm: associated sustained potentials and candidate synaptic generators. Brain Res 615:310-327. CrossRef Medline

Bressler SL, Freeman WJ (1980) Frequency analysis of olfactory system EEG in cat, rabbit, and rat. Electroencephalogr Clin Neurophysiol 50:19-24. CrossRef Medline

Burwell RD, Amaral DG (1998) Cortical afferents of the perirhinal, postrhinal, and entorhinal cortices of the rat. J Comp Neurol 398:179-205. CrossRef Medline

Buzsáki G (1986) Hippocampal sharp waves: their origin and significance. Brain Res 398:242-252. CrossRef Medline 
Buzsáki G (2002) $\theta$ oscillations in the hippocampus. Neuron 33:325-340. CrossRef Medline

Buzsáki G, Draguhn A (2004) Neuronal oscillations in cortical networks. Science 304:1926-1929. CrossRef Medline

Buzsáki G, Moser EI (2013) Memory, navigation and $\theta$ rhythm in the hippocampal-entorhinal system. Nat Neurosci 16:130-138. CrossRef Medline

Buzsáki G, Silva FL (2012) High frequency oscillations in the intact brain. Prog Neurobiol 98:241-249. CrossRef Medline

Buzsáki G, Czopf J, Kondákor I, Kéllenyi L (1986) Laminar distribution of hippocampal rhythmic slow activity (RSA) in the behaving rat: currentsource density analysis, effects of urethane and atropine. Brain Res 365: 125-137. CrossRef Medline

Buzsáki G, Buhl DL, Harris KD, Csicsvari J, Czéh B, Morozov A (2003) Hippocampal network patterns of activity in the mouse. Neuroscience 116:201-211. CrossRef Medline

Cajal SR (1911) Histologie du systeme nerveux de l'homme et des vertébres T.2. Paris: A. Maloine.

Canning KJ, Wu K, Peloquin P, Klosterman F, Leung LS (2006) Physiology of the entorhinal and perirhinal projections to the hippocampus studied by current source density analysis. Ann N Y Acad Sci 911:55-72. CrossRef Medline

Carnevali L, Sgoifo A, Trombini M, Landgraf R, Neumann ID, Nalivaiko E (2013) Different patterns of respiration in rat lines selectively bred for high and low anxiety. PLoS One 8:e64519. CrossRef Medline

Chapman CA, Lacaille JC (1999) Cholinergic induction of $\theta$-frequency oscillations in hippocampal inhibitory interneurons and pacing of pyramidal cell firing. J Neurosci 19:8637-8645. Medline

Chrobak JJ, Buzsáki G (1998) $\gamma$ oscillations in the entorhinal cortex of the freely behaving rat. J Neurosci 18:388-398. Medline

Clement EA, Richard A, Thwaites M, Ailon J, Peters S, Dickson CT (2008) Cyclic and sleep-like spontaneous alternations of brain state under urethane anaesthesia. PLoS One 3:e2004. CrossRef Medline

Colgin LL, Moser EI (2010) $\gamma$ oscillations in the hippocampus. Physiology 25:319-329. CrossRef Medline

Crosfill ML, Widdicombe JG (1961) Physical characteristics of the chest and lungs and the work of breathing in different mammalian species. J Physiol 158:1-14. Medline

Csicsvari J, Hirase H, Czurkó A, Mamiya A, Buzsáki G (1999) Fast network oscillations in the hippocampal CA1 region of the behaving rat. J Neurosci 19:RC20. Medline

Delorme A, Makeig S (2004) EEGLAB: an open source toolbox for analysis of single-trial EEG dynamics including independent component analysis. J Neurosci Methods 134:9-21. CrossRef Medline

Depuy SD, Kanbar R, Coates MB, Stornetta RL, Guyenet PG (2011) Control of breathing by raphe obscurus serotonergic neurons in mice. J Neurosci 31:1981-1990. CrossRef Medline

Dragoi G, Carpi D, Recce M, Csicsvari J, Buzsáki G (1999) Interactions between hippocampus and medial septum during sharp waves and $\theta$ oscillation in the behaving rat. J Neurosci 19:6191-6199. Medline

Eichenbaum H (1999) Using olfaction to study memory. Ann N Y Acad Sci 855:857-869. CrossRef Medline

Eichenbaum H, Morton TH, Potter H, Corkin S (1983) Selective olfactory deficits in case H.M. Brain 106:459-472. CrossRef Medline

Eichenbaum H, Kuperstein M, Fagan A, Nagode J (1987) Cue-sampling and goal-approach correlates of hippocampal unit activity in rats performing an odor-discrimination task. J Neurosci 7:716-732. Medline

Eichenbaum H, Fagan A, Mathews P, Cohen NJ (1988) Hippocampal system dysfunction and odor discrimination learning in rats: impairment or facilitation depending on representational demands. Behav Neurosci 102: 331-339. CrossRef Medline

Eichenbaum H, Mathews P, Cohen NJ (1989) Further studies of hippocampal representation during odor discrimination learning. Behav Neurosci 103:1207-1216. CrossRef Medline

European Science Foundation (2001) Use of animals in research. In: European Science Foundation Policy Briefings, Ed 2. Strasbourg: European Science Foundation.

Fontanini A, Bower JM (2006) Slow-waves in the olfactory system: an olfactory perspective on cortical rhythms. Trends Neurosci 29:429-437. CrossRef Medline

Fontanini A, Spano P, Bower JM (2003) Ketamine-xylazine-induced slow
$(<1.5 \mathrm{~Hz})$ oscillations in the rat piriform (olfactory) cortex are functionally correlated with respiration. J Neurosci 23:7993-8001. Medline

Freeman WJ (1978) Spatial properties of an EEG event in the olfactory bulb and cortex. Electroencephalogr Clin Neurophysiol 44:586-605. CrossRef Medline

Freund TF, Buzsáki G (1996) Interneurons of the hippocampus. Hippocampus 6:347-470. Medline

Fujisawa S, Buzsáki G (2011) A 4 Hz oscillation adaptively synchronized prefrontal, VTA, and hippocampal activities. Neuron 72:153-165. CrossRef Medline

Girardeau G, Benchenane K, Wiener SI, Buzsáki G, Zugaro MB (2009) Selective supression of hippocampal ripples impairs spatial memory. Nat Neurosci 12:1222-1223. CrossRef Medline

Grosmaitre X, Santarelli LC, Tan J, Luo M, Ma M (2007) Dual functions of mammalian olfactory sensory neurons as odor detectors and mechanical sensors. Nat Neurosci 10:348-354. CrossRef Medline

Haberly LB, Price JL (1977) The axonal projection patterns of the mitral and tufted cells of the olfactory bulb in the rat. Brain Res 129:152-157. CrossRef Medline

Harris KD, Henze DA, Hirase H, Leinekugel X, Dragoi G, Czurkó A, Buzsáki G (2002) Spike train dynamics predicts $\theta$-related phase precession in hippocampal pyramidal cells. Nature 417:738-741. CrossRef Medline

Hu H, Vervaeke K, Storm JF (2002) Two forms of electrical resonance at $\theta$ frequencies, generated by $\mathrm{M}$-current, $\mathrm{h}$-current and persistent $\mathrm{Na}^{+}$current in rat hippocampal cells. J Physiol 545:783-805. CrossRef Medline

Institute of Laboratory Animal Research (1996) Guide for the care and use of laboratory animals. Washington, DC: National Academies, Commission on Life Sciences, National Research Council.

Kaut KP, Bunsey MD, Riccio DC (2003) Olfactory learning and memory impairment following lesions to the hippocampus and perirhinal-entorhinal cortex. Behav Neurosci 117:304-319. CrossRef Medline

Kay LM (2005) $\theta$ oscillations and sensorimotor performance. Proc Natl Acad Sci U S A 102:8386-8391. CrossRef Medline

Kay LM, Beshel J, Brea J, Martin C, Rojas-Líbano D, Kopell N (2009) Olfactory oscillations: the what, how and what for. Trends Neurosci 32:207214. CrossRef Medline

Kerr KM, Agster KL, Furtak SC, Burwell RD (2007) Functional neuroanatomy of the parahippocampal region: the lateral and medial entorhinal areas. Hippocampus 17:697-708. CrossRef Medline

Klingberg F, Pickenhain L (1965) Über langsame atemsynchrone Potentiale vom Bulbus olfactorius der Ratte. Acta Biol Med Ger 14:749-763. Medline

Kosel KC, Van Hoesen GW, West JR (1981) Olfactory bulb projections to the parahippocampal area of the rat. J Comp Neurol 198:467-482. CrossRef Medline

Kramis R, Vanderwolf CH, Bland BH (1975) Two types of hippocampal rhythmical slow activity in both the rabbit and the rat: relations to behavior and effects of atropine, diethyl ether, urethane, and pentobarbital. Exp Neurol 49:58-85. CrossRef Medline

Leung LS, Yu HW (1998) $\theta$-frequency resonance in hippocampal CA1 neurons in vitro demonstrated by sinusoidal current injection. J Neurophysiol 79:1592-1596. Medline

Lisman JE, Jensen O (2013) The $\theta-\gamma$ neural code. Neuron 77:1002-1016. CrossRef Medline

Liu P, Bilkey DK (1997) Parallel involvement of perirhinal and lateral entorhinal cortex in the polysynaptic activation of hippocampus by olfactory inputs. Hippocampus 7:296-306. CrossRef Medline

Macrides F (1975) Temporal relationships between hippocampal slow waves and exploratory sniffing in hamsters. Behav Biol 14:295-308. CrossRef Medline

Macrides F, Eichenbaum HB, Forbes WB (1982) Temporal relationship between sniffing and the limbic $\theta$ rhythm during odor discrimination reversal learning. J Neurosci 2:1706-1717. Medline

Margrie TW, Schaefer AT (2003) $\theta$ oscillation coupled spike latencies yield computational vigour in a mammalian sensory system. J Physiol 546:363374. CrossRef Medline

Martin C, Gervais R, Messaoudi B, Ravel N (2006) Learning-induced oscillatory activities correlated to odour recognition: a network activity. Eur J Neurosci 23:1801-1810. CrossRef Medline

McNaughton N, Kocsis B, Hajós M (2007) Elicited hippocampal $\theta$ rhythm: a screen for anxiolytic and procognitive drugs through changes in hippocampal function? Behav Pharmacol 18:329-346. CrossRef Medline 
Mitzdorf U (1985) Current source-density method and application in cat cerebral cortex: investigation of evoked potentials and EEG phenomena. Physiol Rev 65:37-100. Medline

Montgomery SM, Buzsáki G (2007) $\gamma$ oscillations dynamically couple hippocampal CA3 and CA1 regions during memory task performance. Proc Natl Acad Sci U S A 104:14495-14500. CrossRef Medline

Moore JD, Deschênes M, furuta T, Huber D, Smear MC, Demers M, Kleinfeld D (2013) Hierarchy of orofacial rhythms revealed through whisking and breathing. Nature 497:205-210. CrossRef Medline

Nicholson C, Freeman JA (1975) Theory of current source-density analysis and determination of conductivity tensor for anuran cerebellum. J Neurophysiol 38:356-368. Medline

O'Keefe J, Recce ML (1993) Phase relationship between hippocampal place units and the EEG $\theta$ rhythm. Hippocampus 3:317-330. CrossRef Medline

Otto T, Eichenbaum H (1992) Complementary roles of the orbital prefrontal cortex and the perirhinal-entorhinal cortices in an odor-guided delayed-nonmatching-to-sample task. Behav Neurosci 106:762-775. CrossRef Medline

Paxinos G, Franklin KBJ (2001) The mouse brain in stereotaxic coordinates. San Diego: Academic.

Scheffer-Teixeira R, Belchior H, Caixeta FV, Souza BC, Ribeiro S, Tort AB (2012) Theta phase modulates multiple layer-specific oscillations in the CA1 region. Cereb Cortex 22:2404-2414. CrossRef Medline

Scheffzük C, Kukushka VI, Vyssotski AL, Draguhn A, Tort AB, Brankačk J (2011) Selective coupling between $\theta$ phase and neocortical fast $\gamma$ oscillations during REM-sleep in mice. PLoS One 6:e28489. CrossRef Medline

Schwerdtfeger WK, Buhl EH, Germroth P (1990) Disynaptic olfactory input to the hippocampus mediated by stellate cells in the entorhinal cortex. J Comp Neurol 292:163-177. CrossRef Medline

Shipley MT, Adamek GD (1984) The connections of the mouse olfactory bulb: a study using orthograde and retrograde transport of wheat germ agglutinin conjugated to horseradish peroxidase. Brain Res Bull 12:669688. CrossRef Medline

Skaggs WE, McNaughton BL, Wilson MA, Barnes CA (1996) $\theta$ phase precession in hippocampal neuronal populations and the compression of temporal sequences. Hippocampus 6:149-172. CrossRef Medline

Smith JC, Abdala AP, Borgmann A, Rybak IA, Paton JF (2013) Brainstem respiratory networks: building blocks and microcircuits. Trends Neurosci 36:152-162. CrossRef Medline

Staubli U, Ivy G, Lynch G (1984) Hippocampal denervation causes rapid forgetting of olfactory information in rats. Proc Natl Acad Sci U S A 81: 5885-5887. CrossRef Medline

Staubli U, Fraser D, Kessler M, Lynch G (1986) Studies on retrograde and anterograde amnesia of olfactory memory after denervation of the hippocampus by entorhinal cortex lesions. Behav Neural Biol 46:432-444. CrossRef Medline

Steriade M, Nuñez A, Amzica F (1993) A novel slow ( $<1 \mathrm{~Hz}$ ) oscillation of neocortical neurons in vivo: depolarizing and hyperpolarizing components. J Neurosci 13:3252-3265. Medline

Steward O, Scoville SA (1976) Cells of origin of entorhinal cortical afferents to the hippocampus and fascia dentate of the rat. J Comp Neurol 169:347370. CrossRef Medline
Stewart M, Fox SE (1989) Detection of an atropine-resistant component of the hippocampal $\theta$ rhythm in urethane-anesthetized rats. Brain Res 500: 55-60. CrossRef Medline

Stewart M, Fox SE (1991) Do septal neurons pace the hippocampal $\theta$ rhythm? Trends Neurosci 13:163-168. CrossRef Medline

Tort AB, Komorowski RW, Manns JR, Kopell NJ, Eichenbaum H (2009) $\theta-\gamma$ coupling increases during the learning of item-context associations. Proc Natl Acad Sci U S A 106:20942-20947. CrossRef Medline

Tort AB, Komorowski R, Eichenbaum H, Kopell N (2010) Measuring phase-amplitude coupling between neuronal oscillations of different frequencies. J Neurophysiol 104:1195-1210. CrossRef Medline

Vanderwolf $\mathrm{CH}$ (1969) Hippocampal electrical activity and voluntary movement in the rat. Electroencephalogr Clin Neurophysiol 26:407-418. CrossRef Medline

Vanderwolf CH (1992) Hippocampal activity, olfaction, and sniffing: an olfactory input to the dentate gyrus. Brain Res 593:197-208. CrossRef Medline

Vanderwolf CH (2001) The hippocampus as an olfacto-motor mechanism: were the classical anatomists right after all? Behav Brain Res 127:25-47. CrossRef Medline

Wesson DW, Borkowski AH, Landreth GE, Nixon RA, Levy E, Wilson DA (2011) Sensory network dysfunction, behavioral impairments, and their reversibility in an Alzheimer's $\beta$-amyloidosis mouse model. J Neurosci 31:15962-15971. CrossRef Medline

Wilson RC, Steward O (1978) Polysynaptic activation of the dentate gyrus of the hippocampal formation: an olfactory input via the lateral entorhinal cortex. Exp Brain Res 33:523-534. Medline

Winson J (1976) Hippocampal $\theta$ rhythm: II. Depth profiles in the freely moving rabbit. Brain Res 103:71-79. CrossRef Medline

Witter MP, Groenewegen HJ (1984) Laminar origin and septotemporal distribution of entorhinal and perirhinal projections to the hippocampus in the cat. J Comp Neurol 224:371-385. CrossRef Medline

Witter MP, Groenewegen HJ, Lopes da Silva FH, Lohman AH (1989) Functional organization of the extrinsic and intrinsic circuitry of the parahippocampal region. Prog Neurobiol 33:161-253. CrossRef Medline

Wouterlood FG, Nederlof J (1983) Terminations of olfactory afferents on layer II and III neurons in the entorhinal area: degeneration-Golgielectron microscopic study in the rat. Neurosci Lett 36:105-110. CrossRef Medline

Wouterlood FG, Mugnaini E, Nederlof J (1985) Projection of the olfactory bulb efferents to layer I GABAergic neurons in the entorhinal area: combination of anterograde degeneration and immunoelectron microscopy in rat. Brain Res 343:283-296. CrossRef Medline

Xu W, Wilson DA (2012) Odor-evoked activity in the mouse lateral entorhinal cortex. Neuroscience 223:12-20. CrossRef Medline

Ylinen A, Bragin A, Nádasdy Z, Jandó G, Szabó I, Sik A, Buzsáki G (1995a) Sharp wave-associated high-frequency oscillation $(200 \mathrm{~Hz})$ in the intact hippocampus: network and intracellular mechanisms. J Neurosci 15:30 46. Medline

Ylinen A, Soltész I, Bragin A, Penttonen M, Sik A, Buzsáki G (1995b) Intracellular correlates of hippocampal $\theta$ rhythm in identified pyramidal cells, granule cells, and basket cells. Hippocampus 5:78-90. CrossRef Medline 